\title{
Patterns of streamflow regimes along the river network: The case of the Thur River
}

\author{
Behnam Doulatyari ${ }^{\mathrm{a}, \mathrm{b}, *}$, Andrea Betterle $\mathrm{e}^{\mathrm{a}, \mathrm{b}, \mathrm{c}}$, Dirk Radny $^{\mathrm{a}}$, Elisa Alessi Celegon ${ }^{\mathrm{d}}$, \\ Pietro Fanton ${ }^{\mathrm{d}}$, Mario Schirmer ${ }^{\mathrm{a}, \mathrm{b}}$, Gianluca Botter ${ }^{\mathrm{c}}$ \\ ${ }^{a}$ EAWAG Swiss Federal Institute of Aquatic Science and Technology, Department of Water Resources \\ and Drinking Water, Duebendorf, Switzerland \\ ${ }^{b}$ University of Neuchatel, The Centre of Hydrogeology and Geothermics (CHYN), Neuchatel, \\ Switzerland \\ ${ }^{c}$ University of Padova, Department ICEA and International Center for Hydrology "Dino Tonini", \\ Padua, Italy \\ ${ }^{d}{ }_{4}$ Consulting S.r.l., via Barroccio dal Borgo 1, 35124 Padova, Italy
}

\begin{abstract}
A modeling framework for point-wise prediction of the probability density function and flow duration curve of streamflows along complex river networks is presented. The predictions are based on catchment-scale climatic and morphological features, without calibration on observed discharge time-series. The framework was applied to a test basin in north-eastern Switzerland, and relevant flow statistics were validated at six subcatchment outlets with satisfactory results. Spatial patterns of flow regime exhibit a strong climatic signature, mostly driven by reduced rainfall depths and increasing effective rainfall frequency in the downstream areas. The increasing non-linearity of the catchment response with contributing area is reflected by the observed increase in the recession parameters along the main river channel. This framework offers a novel approach for assessing the spatial patterns of streamflows based on limited information, which is important for evaluation of human and ecological functions in riverine systems.
\end{abstract}

Keywords: Geo-database, Streamflow Regime, Stochastic Model, Flow Duration Curve, Physically-based, River Network

\footnotetext{
${ }^{*}$ Corresponding author

Email address: behnam.doulatyari@eawag.ch (Behnam Doulatyari)
} 


\section{Introduction}

The natural spatial variability of flow regimes within riverine systems is a major control for both human and ecological functions in river corridors [e.g. Bertuzzo et al., 2012; Ziv et al., 2012; Jaeger et al., 2014; Mcluney et al., 2014]. These spatial patterns are a complex by-product of climatic and morphological features of the contributing catchment. Modeling and predicting this variability and the underlying drivers, particularly where discharge data scarcity is a limiting factor, represents an important topic of research.

9 The main features of the flow regime for any given point along the network can 10 be summarized through streamflow statistics, such as the probability density function 11 (PDF) of streamflows and the flow duration curve (FDC)[Vogel and Fennessey 1995]. 12 Spatially explicit characterization of these flow statistics has received much attention in 3 recent years, and diverse modeling approaches have been proposed. Spatially distributed 14 models are complex and capable of estimating the spatiotemporal heterogeneity of main hydrological processes in a study area [Kumar et al., 2013; Murphy et al., 2013; Ryo et al., 2015]. However, they often depend on a large number of unknown parameters that must 17 be calibrated. This number can be reduced through utilization of hydrological response 18 units [Flügel, 1995; Gurtz et al., 2005; Viviroli et al., 2009] or regionalization techniques [Götzinger and Bárdossy, 2006; Kling and Gupta, 2009; Samaniego et al., 2010; Singh et al., 2012]. However, despite recent progress in parametrization across scales [Kumar et al., 2013], parameters calibrated at a particular spatial resolution are often not applicable 22 to other scales.

Geostatistical models have proved capable of predicting a variety of hydrometric 24 indices and one, or a series of, flow quantiles based on empirical correlations among 25 available discharge observations [Castellarin 2014; Pugliese, et al., 2014; Laaha et al., 2014]. However, statistical models often do not directly account for flow generation ${ }_{27}$ processes, require observed streamflow time series, and are very sensitive to data quality 28 and density [Blöschl et al., 2013; Müller and Thompson, 2016].

Stochastic, process-based models have been demonstrated to be well suited for preso diction of the complete flow duration curve [Botter et al., 2007, 2009; Muneepeerakul et 31 al., 2007; Schaefli et al., 2014; Pumo et al., 2013; Ceola et al., 2014; Müller et al., 2014]. 
They often use a limited number of physically meaningful parameters, with low compu33 tational burden, to mechanistically link the drivers, state and hydrologic response of the 34 catchment [Müller and Thompson, 2015]. process-based models can also be applied in 35 the absence of long term discharge time series, as they require minimal or no calibra36 tion [Doulatyari et al., 2015]. Such attributes make this category of model a valuable 37 alternative for predicting the spatial variability of flow regimes, especially in cases where 38 hydrometric stations are lacking. To date, this type of models have only been applied to 39 individual catchment outlets.

In this paper we employ the stochastic analytical model developed by Botter et al., 412007 to provide a framework capable of estimating the complete FDCs, at any arbitrary 42 point along a complex river network. The model has four physically based parameters, 43 which are estimated for each point along the network, without calibration to discharge 44 time series. The estimation process accounts for the heterogeneity of the underlying 45 climatic and geomorphic drivers by quantifying the spatial patterns of effective rainfall 46 and recession features, as well as the interplay between these driver in all the relevant 47 contributing areas. The framework was implemented in conjunction with a custom web 48 GIS and geodatabase, based on mainly open source software. The original contribution 49 of this paper is in two main areas: $(i)$ for the first time a parsimonious process based 50 formulation is framed in a spatially explicit setting to analyze the patterns of FDC along 51 the river network; ( $i i)$ scaling relationships for recession parameters and discharge vari52 ability are analyzed. Furthermore, a web GIS tool is developed for the characterization 53 of hydro-climatic patterns which may be useful to research and water managers;

${ }_{54}$ The paper is organized as follows: Sections 2 and 3 presents the essential details ${ }_{55}$ about the study area and summarize the hydro-climatic data used. A brief description 56 of the geo-database and Web GIS platform is also included here. Section 4 outlines the 57 modeling approach as well as the theoretical framework used for estimating the four main ${ }_{58}$ model parameters. Results are presented in Section 5. These include the validation of the model at six outlets, spatial patterns of model parameters and flow regimes, and scaling of recession parameters. Advantages and limitations of the methods used are ${ }_{61}$ discussed in Section 6. Section 7 provides the overall conclusions and implication of this 62 novel modeling method. 
The modeling method was tested on the Thur basin, located in Northeast Switzerland.

65 The Thur river, a tributary of the Rhine river, has a length of approximately $130 \mathrm{~km}$

${ }_{66}$ (Figure 1). It is highly monitored and the contributing catchments shows pronounced

67 gradients of rainfall. Therefore it is very well suited for analyzing the relationship between

68 climate gradients and spatial patterns of flow regimes.

${ }_{69}$ There are 19 rainfall stations evenly distributed within the boundaries of the Thur 70 catchment (Table A.2). Discharge data were available in a set of six nested discharge 71 stations (Table A.1) spanning a wide range of contributing areas (from 16 to $1700 \mathrm{~km}^{2}$ ).

72 The annual mean discharge of the Thur river is $53 \mathrm{~m}^{3} / \mathrm{s}$ and discharge fluctuates rapidly 73 in the entire course of the river, especially after heavy rainfalls in the upper catchment 74 [Cirpka et al., 2007]. The are no significant lakes or reservoirs along the river. The 75 effects of snow dynamics have been observed to be relevant in the headwaters catchment 76 [Seneviratne et al., 2012]. The discharge station Andelfingen represents the outlet for 77 the entire basin (Figure 1). Suitable subsets of these discharge stations that represent a 78 sequence of mutually nested sub-catchments (e.g. Jonschwil, Halden, Andelfingen) can 79 be identified and used to analyze the scaling of hydrological properties and flow regimes.

so The Thur basin can be divided into two main morphologic regions: the upper pre81 alpine section with the maximum altitude of 2500 m.a.s.l. (meters above sea level) at 82 Mount Säntis; and the Swiss plateau with altitudes of approximately 350 m.a.s.l. in ${ }_{83}$ the lower catchment containing the Thur valley aquifer. The geology in the catchment 84 consists of mainly limestone-dominated alpine headwaters, and Molasse sandstones, marls ${ }_{85}$ and Pleistocene unconsolidated sediments in the Swiss plateau [Hayashi et al., 2012]. ${ }_{86}$ Precipitation ranges from $2500 \mathrm{~mm} /$ year in the pre-alpine region to approximately $900-$ ${ }_{87} 1000 \mathrm{~mm} /$ year [Seiz and Foppa, 2007] in the Swiss Plateau. Land use in the Thur basin 88 is distributed as roughly $60 \%$ Agriculture, $30 \%$ Forest, and the rest barren land, surface 89 waters, and urban areas [Abbaspour et al., 2007; Schneider et al., 2011]. 


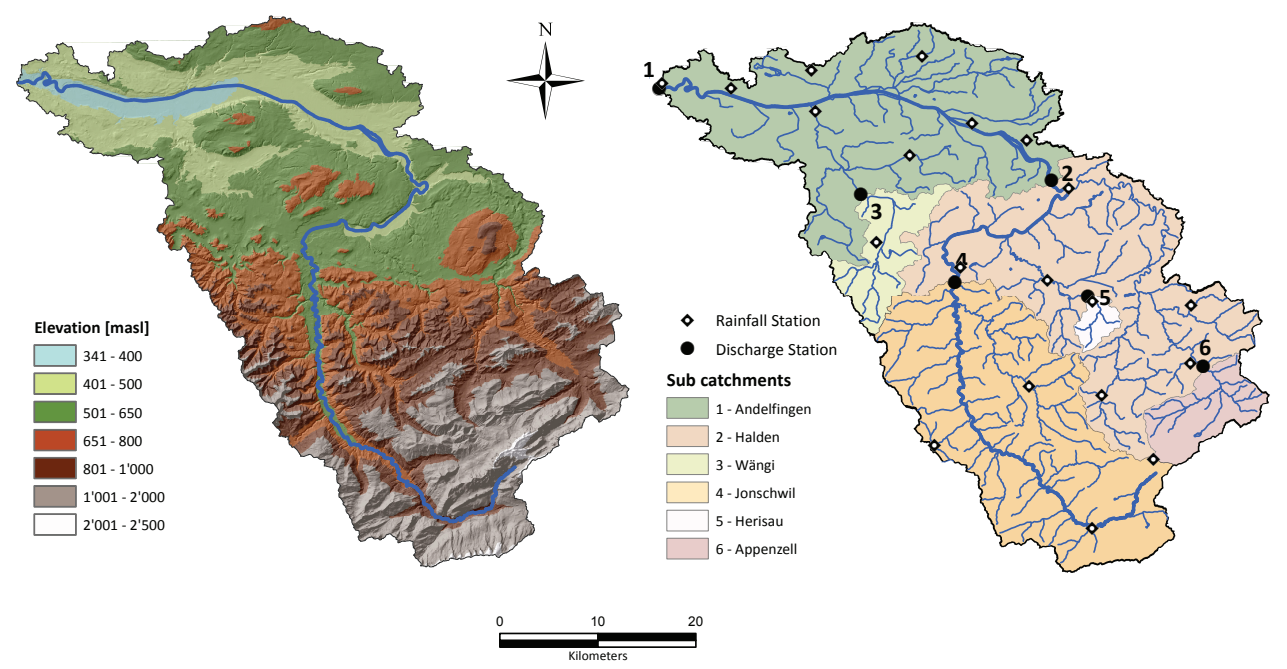

Figure 1: (a) The digital elevation map of the Thur basin. The main morphological sections of the basin, the pre-alpine (to the south and ) and the Swiss plateau (to the north), are easily distinguished. (b) The Thur basin is divided into six sub-catchments. The corresponding gauging stations as well as 19 rainfall stations are marked on the map.

\section{Input Data: Sources and Management}

Input data required by the model include potential evapotranspiration (PET), digital elevation map (DEM), and daily rainfall data. PET data were acquired from 'MODIS global evapotranspiration Project' (MOD16), available from the Montana University (http://www.ntsg. umt.edu), which includes a dataset providing PET at $1 \mathrm{~km}^{2}$ resolution for $10^{9}$ Million $\mathrm{km}^{2}$ global vegetated land areas at 8-day, monthly and annual time resolution. The river network was estimated based on $25 \mathrm{~m}$ DEM obtained from the Federal Office of Topography, Switzerland (http://www.swisstopo.admin.ch/). Daily rainfall data at 19 rainfall stations across the Thur catchment were obtained from the Federal Office of Meteorology and Climatology, Switzerland (http://www.meteoswiss . admin.ch/). Long-term streamflow data were used to validate the results of the model at a set of outlets within the Thur river. Daily discharge data were provided by the Federal Office for the Environment, Switzerland (http://www.bafu.admin.ch/). All hydro-climatic data were obtained for the period of 1970 to 2012.

A geo-database with integrated automatic hydrological model simulations was cre- 


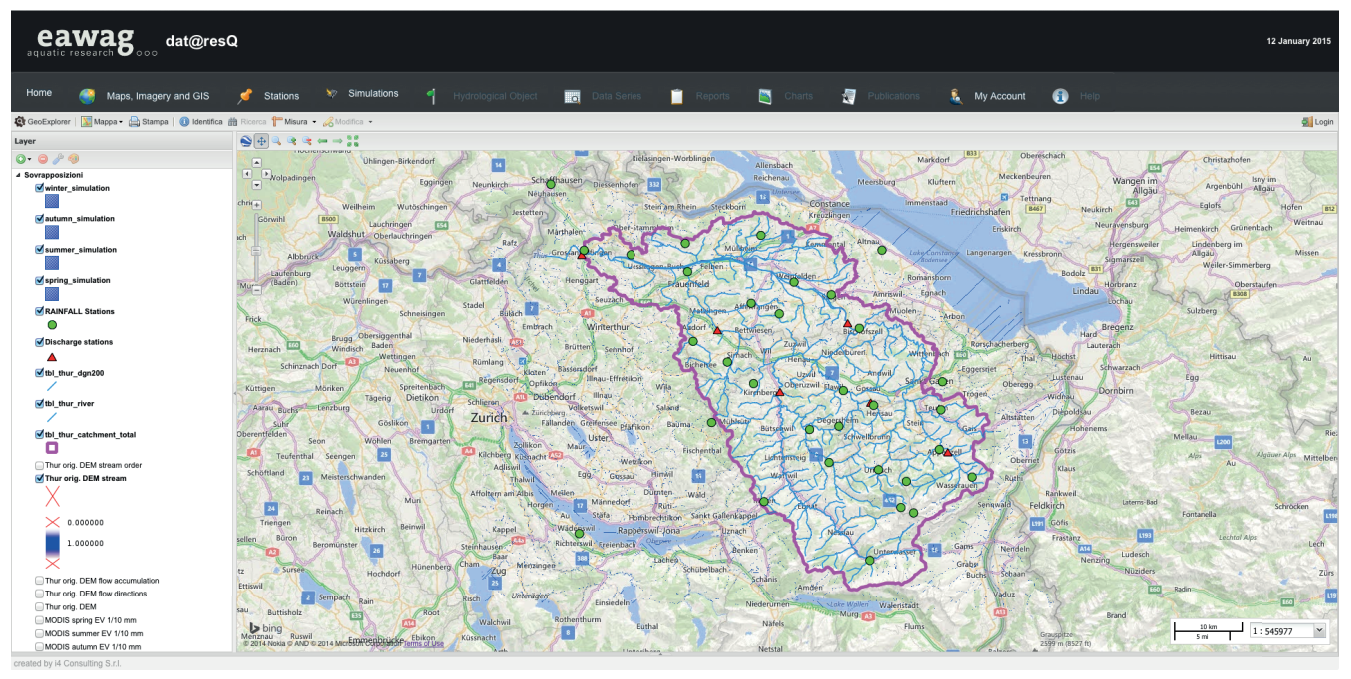

Figure 2: The user interface of the Web GIS platform, built mainly from open source software. The platform offers various data management, visualization and model customization capabilities.

ated for the Thur basin. The database offers a multi-user capable platform with a custom Web-GIS graphical user interface (GUI), data management and query capabilities, and visualizations functions. The methods utilized for model parameter estimation (discussed in Section 4) are incorporated in linked modules that allow for automatic analysis of the input data. Figure 2 shows the interface of and menus of the developed tool. The interface facilitates application for academic research (e.g. virtual laboratories for collaborative projects), and water policy development. A demonstration version of the tool can be accessed at http://demoeawag.i4it.it (user-name: demodemo; password: demodemo).

\section{Methods and Parameter Estimation}

The seasonal PDFs of daily streamflows $(p(Q))$ are predicted by an analytical mechanistic model, where the catchment-scale soil water balance is forced by stochastic rainfall.

Here rain is modeled at the daily timescale, as a marked Poisson process with frequency $\lambda_{P}\left[T^{-1}\right]$ and exponentially distributed depths with average $\alpha[L]$ [Rodriguez-Iturbe, 2000; Porporato et al., 2004; Botter et al., 2007]. Accordingly, the dynamics of the specific streamflow is made up of instantaneous jumps corresponding to rainfall events filling 
the soil water deficit in the root zone (with frequency $\lambda<\lambda_{P}$, and also represented as a marked Poisson process); and the power law decays in between events, as implied by a non-linear catchment-scale storage-discharge relationship [Brutsaert and Nieber 1997; Porporato and Ridolfi, 2003; Kirchner, 2009]. Such power law recession behavior is defined through the recession exponent $a$ and coefficient $K$ (i.e. $\frac{d Q}{d t}=-K Q^{a}$ ).

The analytical expression for $p(Q)$ was defined by Botter et al. [2009] and is presented in Table 1. The model is characterized by four physically based parameters: $\lambda, \alpha, K$ and $a$ (defined above). These parameters incorporate the various hydrologic, climatic and geomorphologic features of the catchment and have been estimated on seasonal basis. For detailed theoretical background and application of this model, the reader is directed to Botter et al. [2009] and Basso et al. [2015], where a more detailed analysis of model assumptions and limitations is provided. The flow duration curve is expressed by the cumulative distribution function $(\mathrm{CDF})$ of $Q$ and can therefore be calculated by integrating equation for $p(Q)$, with closed-form analytical expressions available only for special cases (e.g. $a \in \mathbb{N})$.

Figure 3 outlines the overall modeling approach and the procedure derived in this paper for estimating each parameter for any site along the river network. It is noteworthy to mention, point-wise estimation of model parameters in a spatially explicit set-up poses computation and scientific challenges. From this perspective, the proposed methodology represents a step forward for the application of this type of models in large scale settings. In this section we discuss each module and elaborate on the modeling methods used. A list of all models used and the main model equations are presented in Table 1.

In module (i), daily rainfall data (recorded at 19 climatic stations within the boundaries of the Thur basin) was interpolated and summed to create daily rainfall fields and estimate spatially distributed catchment scale rainfall statistics for individual seasons. The Inverse Distance Weighting (IDW) method was adopted as the interpolation method with power parameter equal to 2 and using 12 nearest rainfall stations per interpolating point.

The frequency of rainfall events, $\lambda_{p}$ was calculated for each point as the relative number of days in which the average rainfall in the upstream contributing area is larger than a given interception threshold ( $1 \mathrm{~mm}$ in this study). To this aim, the daily rainfall 


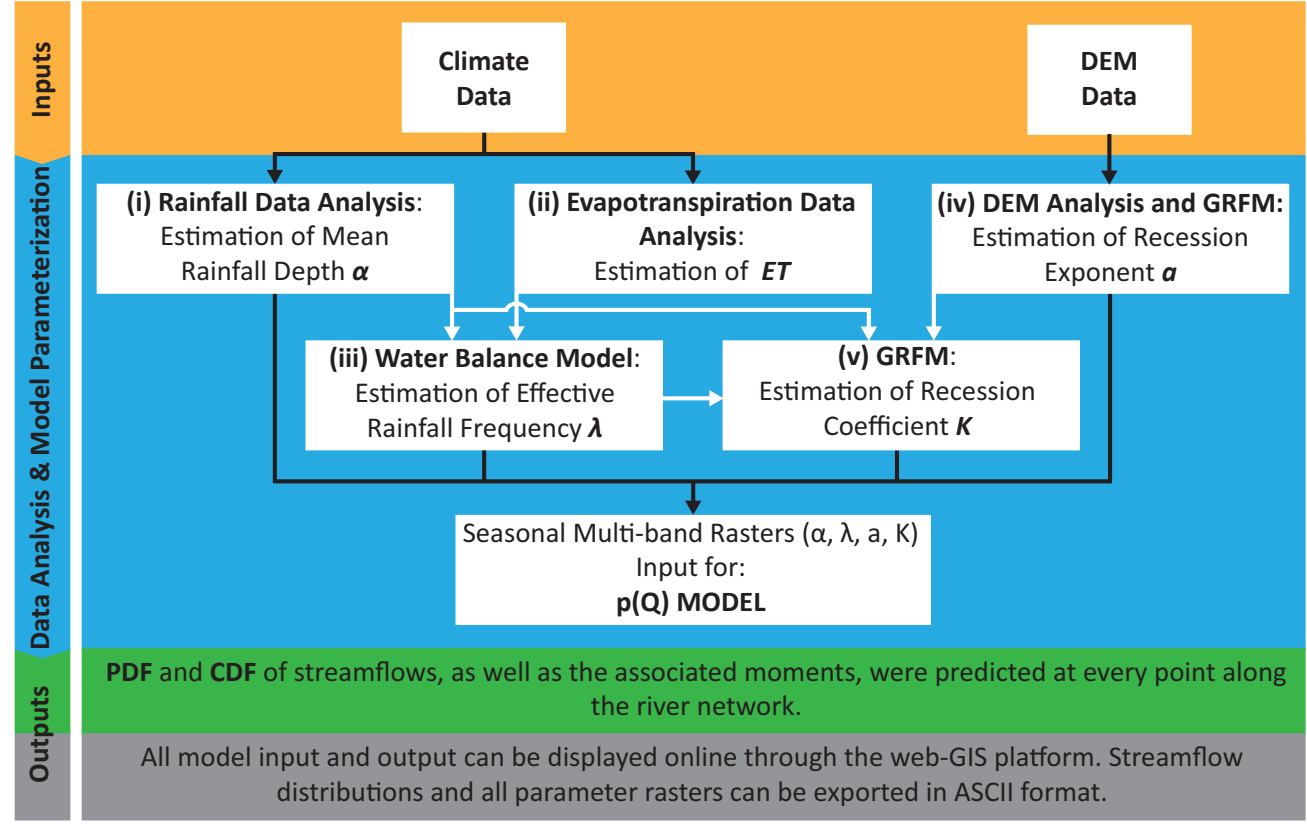

Figure 3: Overall work-flow of the modeling approach. The four main model parameters are estimated at every point (i.e. every pixel along the river network). 
data were analyzed and for each day a raster of 0 or 1 values was created based on the rainfall field in the contributing area. If the upstream averaged rainfall was greater than the threshold then the value at that point was set to 1 , otherwise it was 0 (i.e. it is not raining in the upstream area). For each point, the binary variable is then averaged over the number of days in the record to create seasonal rasters of $\lambda_{p}$. Moreover, the aforementioned rainfall fields were averaged over the number of time steps and over the upstream contribution area of each point, to create seasonal cumulative rainfall fields $(\langle P\rangle)$. Mean rainfall depth $\alpha$ was estimated point-wise as a ratio between the cumulative rainfall and frequency $\left(\alpha=\langle P\rangle / \lambda_{p}\right)$. The observed values of $\alpha$ at the sub-catchment outlets were calculated by averaging the daily rainfall values from all stations in the contributing area for each outlet. The procedure is designed to incorporate the effects of spatial correlation in daily rainfall fields on catchment scale rainfall statistics.

In module (ii), estimation of ET, MODIS seasonal PET rasters were cropped, resampled and geo-referenced according to DEM pixel dimension, and averaged over the contributing area upstream for each point.

The long-term mean of rainfall, based on the streamflow model, is expressed as $\langle P\rangle=$ $\alpha \lambda_{p}$, and the specific discharge can be expressed as $\langle Q\rangle=\alpha \lambda$. The average seasonal runoff coefficient is defined as $\phi=\langle Q\rangle /\langle P\rangle$. Hence, by combining the above equations, the frequency of rainfall events leading to discharge production, $\lambda$, can be calculated as $\lambda=\phi \lambda_{p}$. This is tantamount to assuming that the major effect of root zone soil moisture dynamics is a reduction of the frequency of events [Rodriguez-Iturbe, 2000]. The average seasonal runoff coefficient is estimated at every point by means of calibrated water balance models using precipitation statistics and ET data in the upstream contributing area. In particular, in module (iii), the physically-based analytical stochastic model of soil moisture dynamics presented by Porporato et al. [2004] was used (Table 1). The rooting depth $Z$ was calibrated using observed mean discharge at the outlet and assumed to be constant throughout the basin. Calibrated values are in general close to literature reported values, and the calibration process can be removed entirely following the approach outlined by Doulatyari et al. [2015]. Note that, more refined procedures in which rooting depth is made dependent on soil use and/or topographic curvature can be easily incorporated in the framework. However, given the limited sensitivity of the 
results to the specific value of rooting depth, this has not been presented in this study.

The parameters $a$ and $K$ were estimated based on analysis of the catchment DEM and the geomorphological recession flow model (GRFM) proposed by Biswal and Marani [2010]. This model stipulates that fluctuations of streamflows in time are linked to direct drainage into the active drainage network $(\mathrm{ADN})$. The flow generation rate per unit ADN length is assumed to be constant. Based on this formulation, the recession exponent $a$ is estimated through a least square regression relation between $G(l)$ vs. $N(l)$ (the length of the active drainage, and the number of links in the network at a distance $l$ from the outlet respectively), which is in turn derived from the analysis of the DEM. In module (iv) the Thur basin DEM was analyzed and flow direction and flow accumulation rasters were created. The stream network was then extracted from the flow direction raster using a flow accumulation threshold of $0.09 \mathrm{~km}^{2}$. The recession coefficient $K$ (module $(\mathrm{v}))$ is estimated as a function of mean discharge, the recession exponent $a$, and $\theta$ which is a constant dependent on the speed at which the ADN contracts towards the outlet (empirically found to to be close to $0.2 d^{-1}$ by Doulatyari et al., [2015]). Note that, the recession parameters do change significantly along the network as a result of the variability in topology, vegetation, and climate patterns.

According to the modeling method chosen, the patterns of flow regime along the river network emerge directly as a result of the aggregation of spatial heterogeneity of climate properties along the flow directions (driven by network structure itself), and are not dependent on external calibration procedures.

\section{Results}

\subsection{Model performance}

The agreement between modeled and observed PDFs and CDFs was first assessed through visual inspection. This was further quantified by comparing modeled and observed moments of the PDF, and by computing half the integral difference between the analytical and observed flow PDFs [Botter et al., 2013]. The accuracy of the model estimates for the parameters and selected flow statistics was also analyzed through the Mean Squared Relative Error (MSRE). 


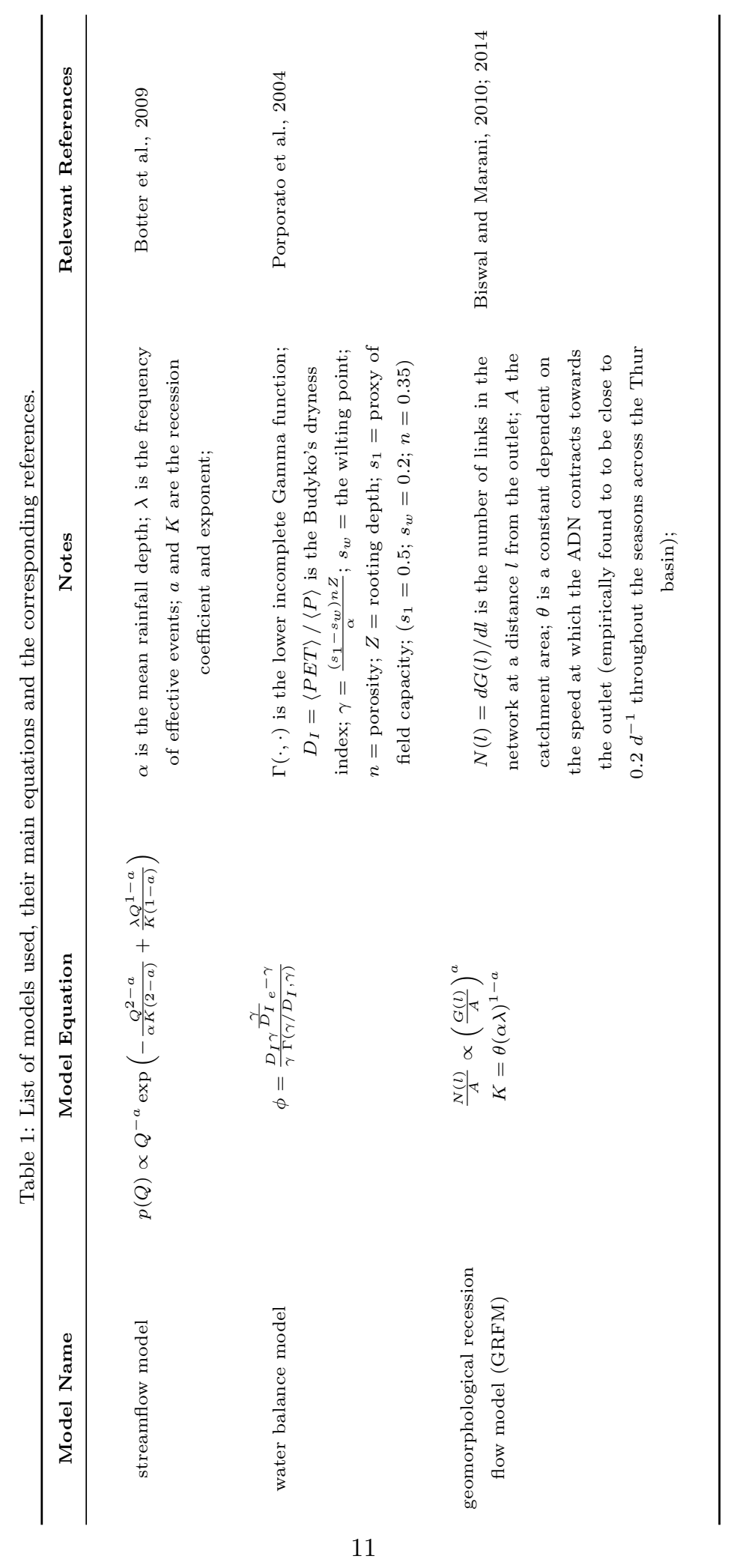


The seasonal values of $\alpha, \lambda, a$ and $K$, estimated using only climate and landscape data (Model Estimates), as well as their observed values (Observed), directly inferred based on discharge data, are presented in Table 2. The estimated values of $\alpha$ are in very good agreement with the observed values at all points $(M S R E=0.003)$. The estimates of $\lambda$ also show good performance in almost all cases $(M S R E=0.032)$. The largest discrepancies occur in Appenzell and generally during the winter season (Figure 4h). Appenzell is located in the highest elevations in the basin where snow dynamics (not explicitly considered in the model formulation) may impact the seasonal water balance. The over estimated value of $\lambda$ during winter (accumulation) and under estimation during the spring and summer (melting) also point in this direction. The estimates of $a$, despite being independent of the season, show very good performance across the basin $(M S R E=$ 0.017). The model estimates of $K$ on the other hand show variable performances across the different sub-catchments and seasons $(M S R E=0.137)$. This could be potentially a result of the contrast between the underlying assumptions of GRFM with regards to the amount of water drained from the subsurface and the setting of the Thur basin, where groundwater dynamics may significantly impact recessions.

Figure 4 presents the observed and modeled seasonal streamflow PDFs at Andelfingen (a through d) and Appenzell (e through f) outlets. The shape of the observed probability distribution is well captured by the model in most cases. However, the PDF moments seem to be slightly over estimated in fall and winter at Appenzell. The underestimation of the PDF mode in winter at Appenzell is likely attributed to snow accumulation and its impact on estimation of $\lambda$. Both sub-catchments demonstrate hump-shaped PDFs across all seasons which is consistent with geographical location and climate of the Thur basin. The associated observed (circles) and modeled (solid line) CDFs are presented in the insets of Figure 4. In order to better represent the behavior of the curves for large streamflows the results are shown in the logarithmic scale. Over all the the shape of the CDF is well represented by the model. However, in a few cases some deviation is visible in the shape of the CDF tail. This is likely related to misestimation of the recession exponent a (see Basso et al., 2015 for more details on the subject), which is estimated through the GRFM model here.

Figure 5 shows the observed and modeled PDFs, and their associated CDF, for the 
Table 2: Estimated seasonal values of model parameters at all sub-catchments in the Thur Basin. The "Observed" values of $\lambda, a$ and $k$ are calculated from observed discharge time series at each outlet, while alpha is calculated by averaging of observed rainfall time series from all stations in the contributing sub-catchment. The "Modeled" columns refer to values estimated by the method outlined in Section 4.

\begin{tabular}{|c|c|c|c|c|c|c|c|c|c|}
\hline \multirow{2}{*}{$\begin{array}{c}\text { sub-catchment } \\
\text { Name }\end{array}$} & \multirow{2}{*}{ Season } & \multicolumn{4}{|c|}{ Modeled } & \multicolumn{3}{|c|}{ Observed } & \multirow[b]{2}{*}{$a[-]$} \\
\hline & & $\alpha[\mathrm{cm}]$ & $\lambda\left[\frac{1}{d}\right]$ & $K\left[\frac{c m^{(1-a)}}{d^{(2-a)}}\right]$ & $a[-]$ & $\alpha[\mathrm{cm}]$ & $\lambda\left[\frac{1}{d}\right]$ & $K\left[\frac{c m^{(1-a)}}{\left.d^{(2-a)}\right]}\right.$ & \\
\hline \multirow[t]{4}{*}{ Andelfingen } & Spring & 0.54 & 0.48 & 1.35 & 2.41 & 0.56 & 0.54 & 1.02 & 2.53 \\
\hline & Summer & 0.74 & 0.33 & 1.46 & 2.41 & 0.75 & 0.33 & 1.31 & 2.20 \\
\hline & Autumn & 0.63 & 0.30 & 2.02 & 2.41 & 0.60 & 0.32 & 2.24 & 2.42 \\
\hline & Winter & 0.50 & 0.46 & 1.60 & 2.41 & 0.50 & 0.45 & 1.11 & 2.30 \\
\hline \multirow[t]{4}{*}{ Appenzell } & Spring & 0.88 & 0.46 & 0.60 & 2.29 & 0.86 & 0.58 & 0.49 & 2.03 \\
\hline & Summer & 1.17 & 0.37 & 0.55 & 2.29 & 1.14 & 0.46 & 0.78 & 2.20 \\
\hline & Autumn & 1.06 & 0.31 & 0.77 & 2.29 & 1.02 & 0.32 & 1.26 & 2.31 \\
\hline & Winter & 0.94 & 0.42 & 0.61 & 2.29 & 0.92 & 0.28 & 0.78 & 2.00 \\
\hline \multirow[t]{4}{*}{ Halden } & Spring & 0.64 & 0.48 & 0.78 & 2.22 & 0.62 & 0.60 & 0.53 & 2.17 \\
\hline & Summer & 0.88 & 0.36 & 0.75 & 2.22 & 0.85 & 0.39 & 1.00 & 2.16 \\
\hline & Autumn & 0.76 & 0.32 & 1.05 & 2.22 & 0.71 & 0.34 & 1.44 & 2.23 \\
\hline & Winter & 0.60 & 0.45 & 0.90 & 2.22 & 0.58 & 0.43 & 0.96 & 2.17 \\
\hline \multirow[t]{4}{*}{ Herisau } & Spring & 0.71 & 0.39 & 0.28 & 1.56 & 0.72 & 0.47 & 0.32 & 1.33 \\
\hline & Summer & 1.01 & 0.30 & 0.27 & 1.56 & 1.03 & 0.32 & 0.49 & 1.53 \\
\hline & Autumn & 0.81 & 0.25 & 0.34 & 1.56 & 0.74 & 0.34 & 0.34 & 1.20 \\
\hline & Winter & 0.58 & 0.36 & 0.33 & 1.56 & 0.55 & 0.51 & 0.55 & 1.70 \\
\hline \multirow[t]{4}{*}{ Jonschwil } & Spring & 0.72 & 0.48 & 0.91 & 2.42 & 0.78 & 0.61 & 0.46 & 2.24 \\
\hline & Summer & 0.98 & 0.37 & 0.85 & 2.42 & 1.07 & 0.37 & 0.78 & 2.09 \\
\hline & Autumn & 0.86 & 0.32 & 1.22 & 2.42 & 0.90 & 0.31 & 1.08 & 2.09 \\
\hline & Winter & 0.72 & 0.45 & 0.99 & 2.42 & 0.76 & 0.37 & 0.87 & 2.14 \\
\hline \multirow[t]{4}{*}{ Wängi } & Spring & 0.62 & 0.37 & 0.70 & 1.98 & 0.66 & 0.35 & 1.26 & 2.54 \\
\hline & Summer & 0.78 & 0.24 & 0.84 & 1.98 & 0.86 & 0.19 & 1.84 & 2.46 \\
\hline & Autumn & 0.73 & 0.23 & 0.95 & 1.98 & 0.67 & 0.24 & 2.42 & 2.60 \\
\hline & Winter & 0.59 & 0.36 & 0.76 & 1.98 & 0.59 & 0.41 & 1.00 & 2.42 \\
\hline
\end{tabular}



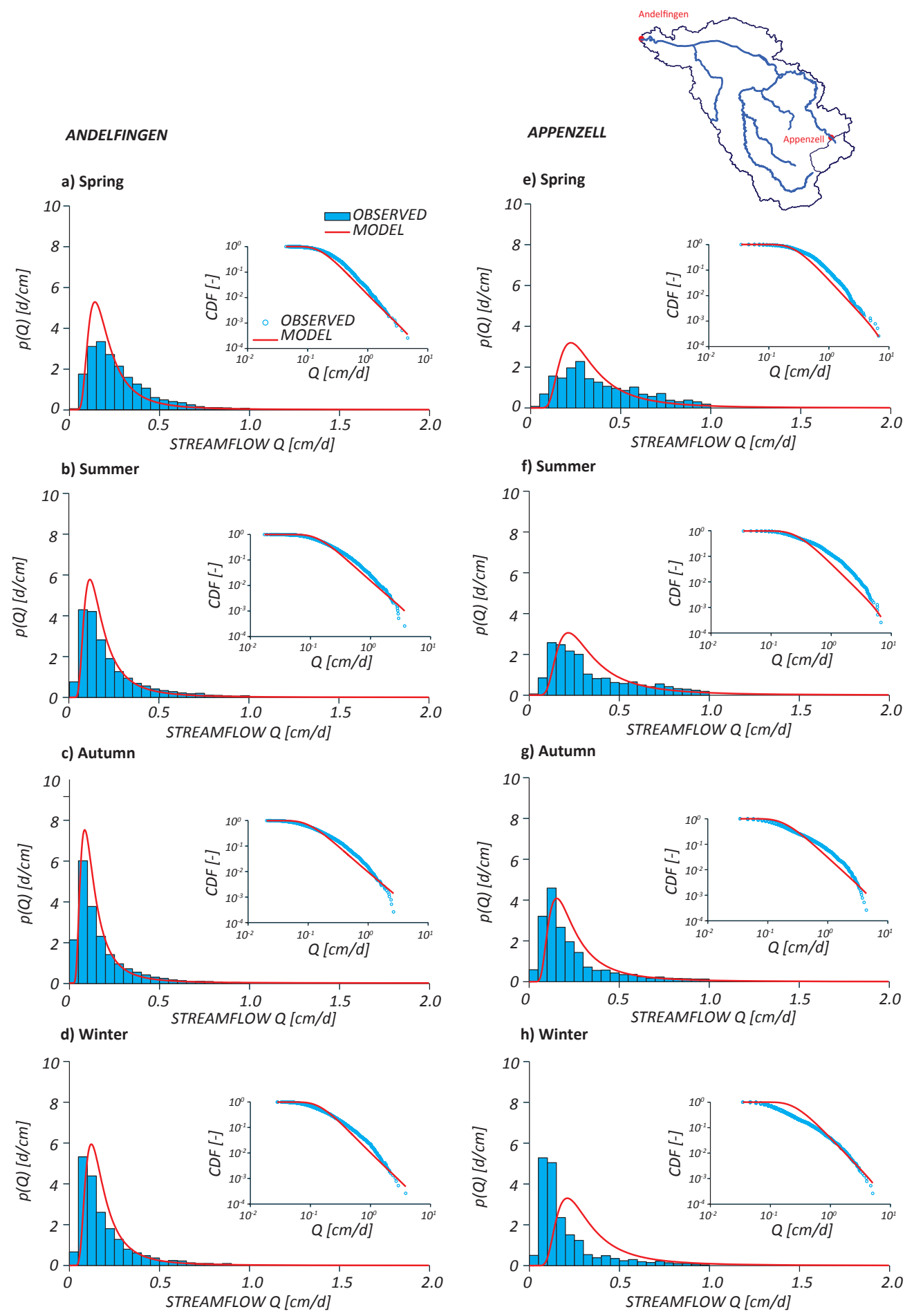

Figure 4: Observed (bars) and modeled (solid lines) PDFs for all seasons at Andelfingen (a-d) and Appenzell (e-h) sub-catchment outlets. The insets show the associated observed (circles) and modeled (solid line) CDFs for each plot on a loglog scale. The integral difference between modeled and observed PDFs is equal to (a) 0.165, (b) 0.165, (c) 0.151, (d) 0.230, (e) 0.203, (f) 0.201, (g) 0.243, and (h) 0.481. 

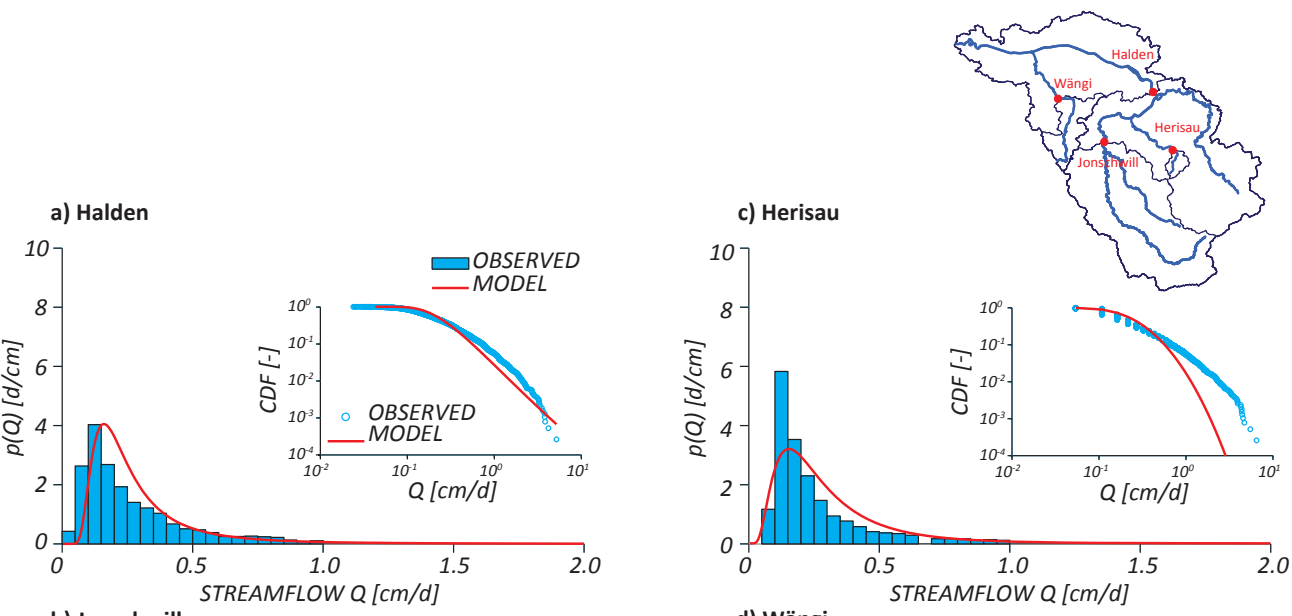

b) Jonschwill
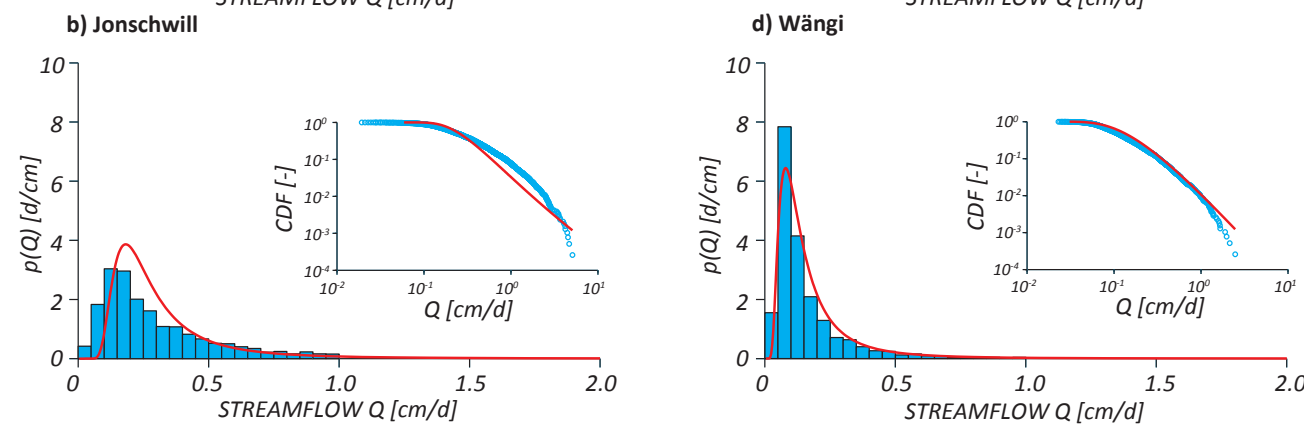

Figure 5: Observed (bars) and modeled (solid lines) PDFs for summer season at (a) Halden, (b) Jonschwil, (c) Herisau, and (d) Wängi. The associated CDF plots (insets) are on a loglog scale. The integral difference between modeled and observed PDFs is equal to (a) 0.192, (b) 0.190, (c) 0.198, and (d) 0.123 .

summer season at the remaining four outlets: (a) Halden, (b) Herisau, (c) Jonschwil, (d) Wängi. Similar to the previous figure, all sub-catchments demonstrate a hump-shaped streamflow PDF. The model reasonably captures the shape of the streamflow PDFs and CDFs in most cases, with the exception of the CDF at Herisau. A slight underestimation of the small discharge events is also noted.

The ability of the model to reproduce observed flow statistics was tested by comparing the observed and modeled moments of the analytical PDF (calculated through numerical integration of the equation of $p(Q))$. Figure 6 shows the modeled seasonal mean discharge $\langle Q\rangle$ and coefficient of variation of daily flows $C V_{Q}$ at all sub-catchments plotted against the corresponding observed values. The model estimations of mean discharge are in good agreement with the corresponding observed values. This suggests that the streamflow 
a)

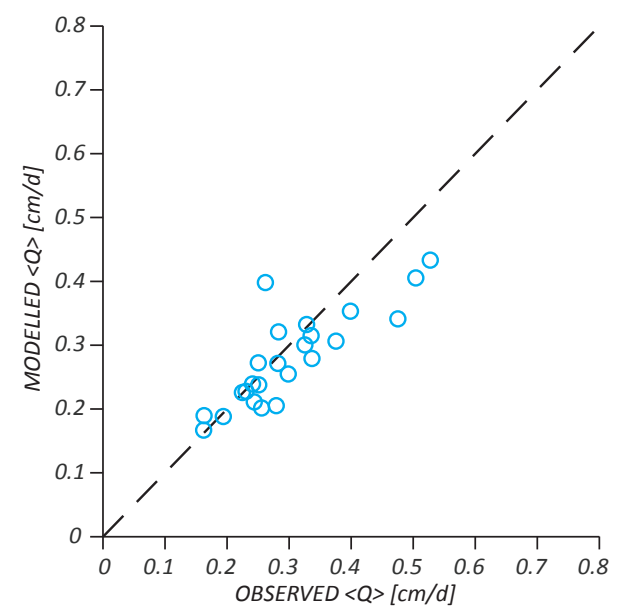

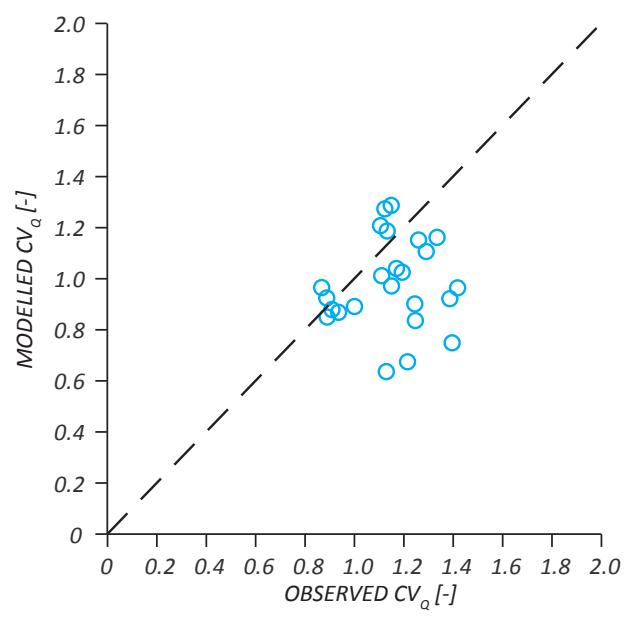

Figure 6: Observed vs. modeled (a) $\langle Q\rangle(M S R E=0.030)$ and (b) $C V_{Q}(M S R E=0.049)$ for all seasons and sub-catchments in the Thur basin. The dashed line represents the 45 degree line (perfect fit).

generation processes is properly represented by the model.

It is noteworthy to mention that the analytical formulation for variance of $Q$ is divergent in case where $a>2$. In order to overcome this issue the upper limit of integration was set equal to the maximum observed specific discharge [Lague et al., 2005]. While the underlying physical causes of this phenomenon require further study, this method provided the most reasonable approach for network-scale studies of this type, where $C V_{Q}$ is calculated for a large number of sites (every point along the network as is the case here). The effect of the divergence of the variance of $p(Q)$ on the variability of sample $C V_{Q}$ is explored in Appendix C. The plot for $C V_{Q}$ shows some scattering, but overall model performance is judged satisfactory considering that no parameter has been calibrated using the observed discharge variability. Note that the range of variability for $C V_{Q}$, in the Thur river, is quite narrow (0.8 to 1.4$)$

\subsection{Spatial patterns of model parameters}

Figures 7 and 8 present the spatial patterns of $\alpha$ and $\lambda$ across the basin for all seasons, respectively. The pre-alpine (southern) section of the basin receives larger amount of rainfall throughout the year as compared to the Swiss plateau (northern section). The rainfall events are less frequent but more intense during the summer, and the opposite 

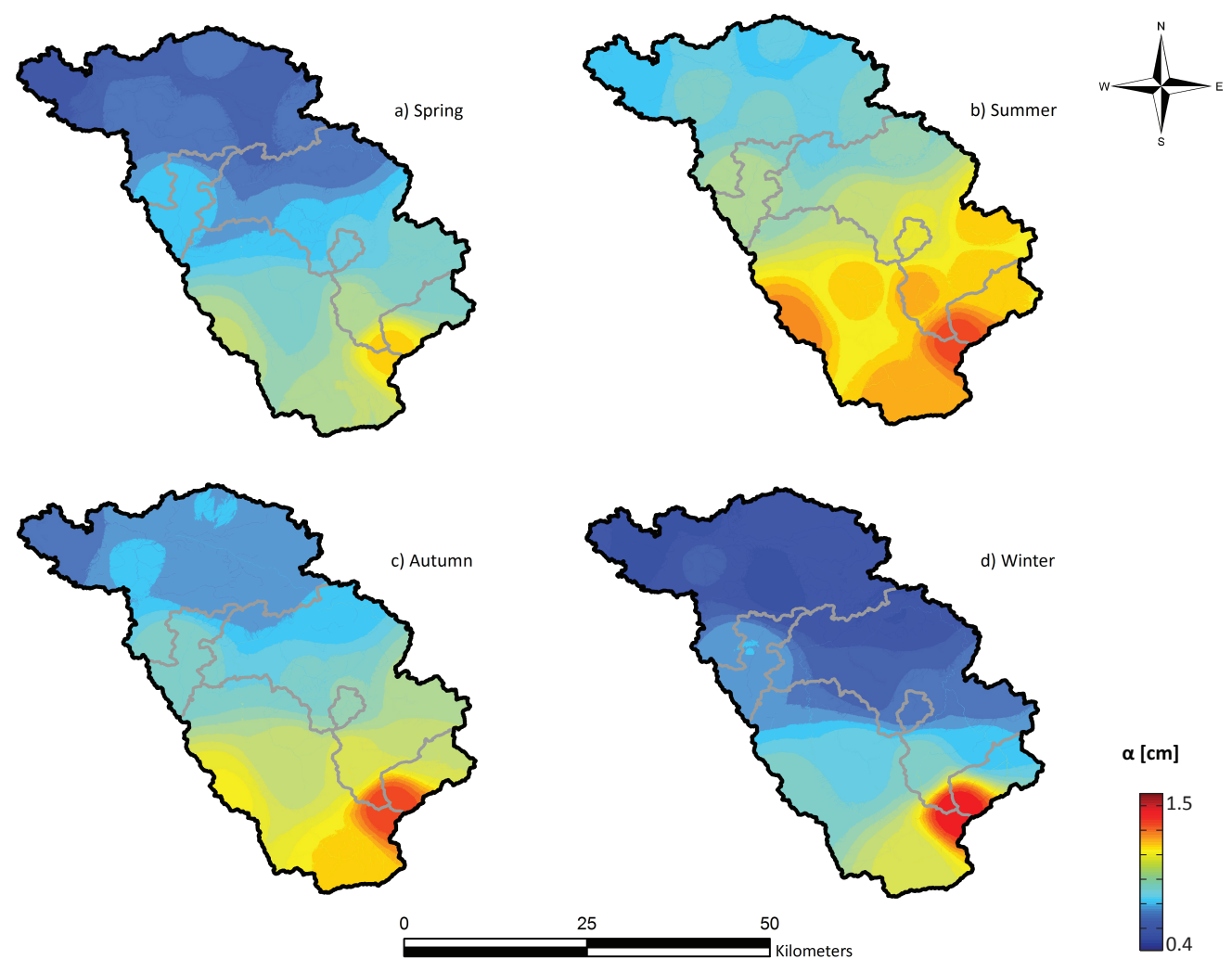

Figure 7: Spatial patterns of $\alpha$ across the Thur basin during all seasons. Larger overall amount of rainfall in the pre-alpine section as compared to the Swiss plateau, and a strong seasonal gradient is noted.

is true for the winter season. The seasonal pattern of $\lambda$ is very well correlated with that of $\alpha$. The spatial pattern of $\lambda$ in the main channel shows a weak increase from the headwaters to the basin outlet, with the exception of the summer season. Moreover, the value of $\lambda$ in the first-order streams of the Swiss plateau is markedly smaller than that of all other streams with similar size.

Figures 9 and 10 display the spatial distribution of $a$ and $K$ across the river network. Note that, as per GRFM assumptions, the value of $a$ is presumed to be constant across the seasons. The value of $a$ is larger in the main channel as compared to the smaller tributaries, and an increasing trend towards the sub-catchment outlets is apparent within individual reaches. Furthermore, a shift in value after the merging of major tributaries is noticeable. These patterns point to an overall increase in non-linearity in the main 

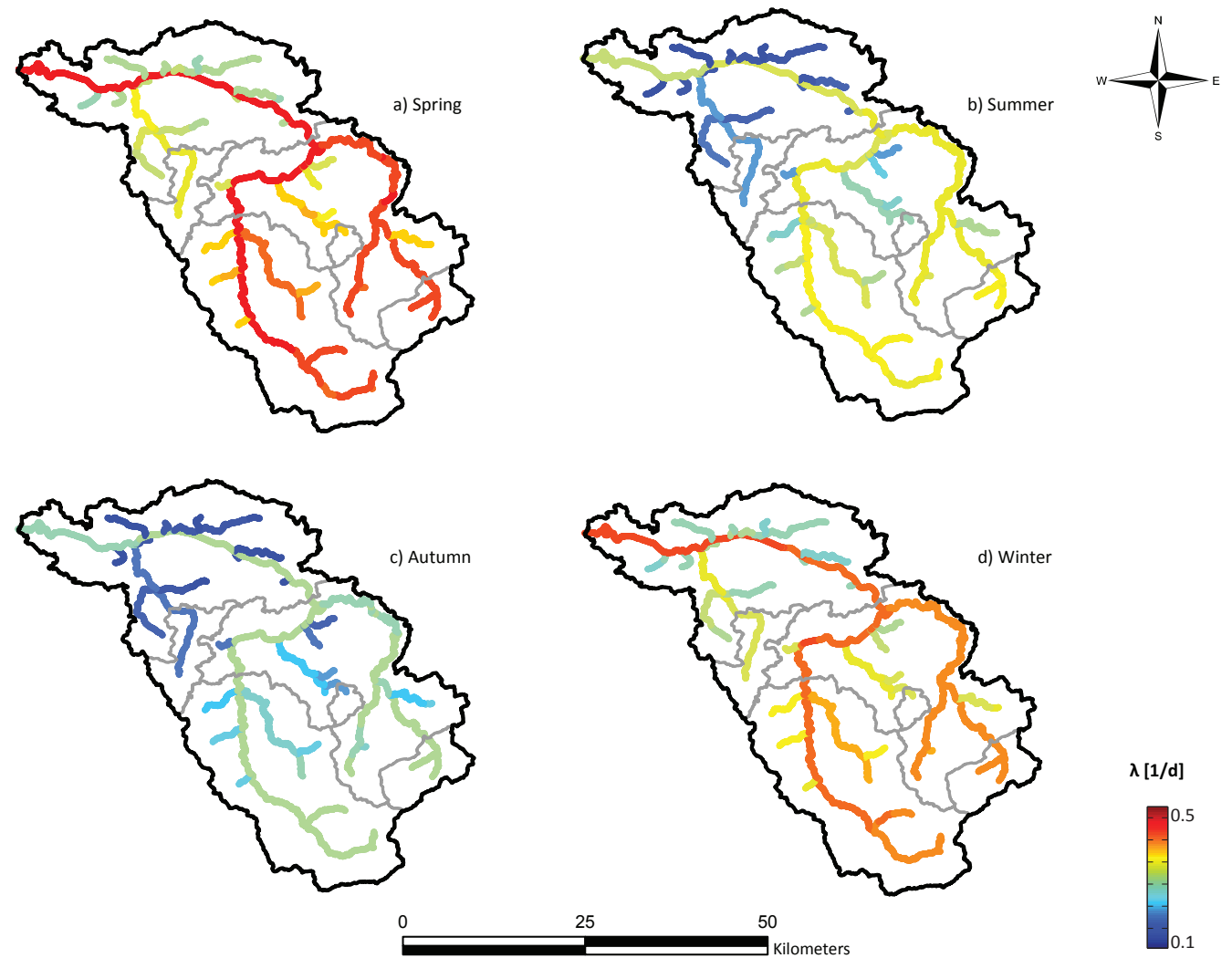

Figure 8: Spatial patterns of $\lambda$ across the Thur basin during all seasons. Rainfall event frequency is high in spring and winter, and lower in summer and autumn. 


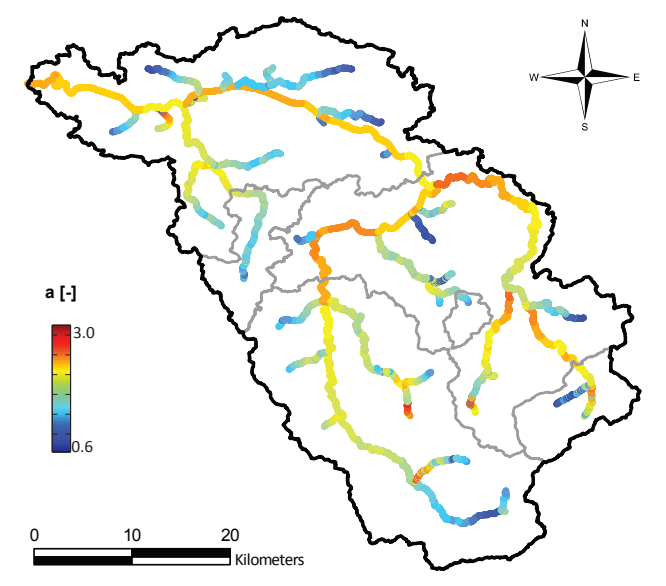

Figure 9: Spatial patterns of $a$ across the Thur basin during all seasons. The value of $a$ is largest in the main channel, with an increasing trend towards the sub-catchment outlets.

channel moving towards the basin outlet. This could be a by-product of increasing heterogeneity in the hydrologic response of the different sub-catchments that contribute to the streamflows at the outlet of larger basins [Harman et al., 2009]. $K$ shows an increasing trend from the headwaters towards the basin outlet across the seasons, with larger values in autumn (the driest season of the year). In fact, $K$ is inversely proportional to the catchment wetness [Shaw et al., 2013].

The spatial variability of flow regimes is the by product of the network-scale variability of these four parameters, which is discussed in the next section.

\subsection{Spatial patterns of flow regimes}

Figures 11 and 12 present the spatial pattern of $\langle Q\rangle$ and $C V_{Q}$ across the basin for each season. The spatial patterns of $\langle Q\rangle$ show a decreasing trend from the pre-alpine section towards the plateau, while the seasonal patterns mirror the seasonality of the climate. This points to the climatic gradient being the main driver. Figure 12 shows a complex pattern of $C V_{Q}$ from upstream to downstream which is the result of two contrasting effects: $(i)$ the increase of $a$ with increasing size of contribution area, which leads to enhanced variability of $Q$ in larger catchments; and (ii) the increase of $\lambda$ and decrease of $\alpha$ with increase in size of the contributing area, which instead tends to reduce the flow variability in larger catchments. The range of $C V_{Q}$ along the network is quite narrow, 

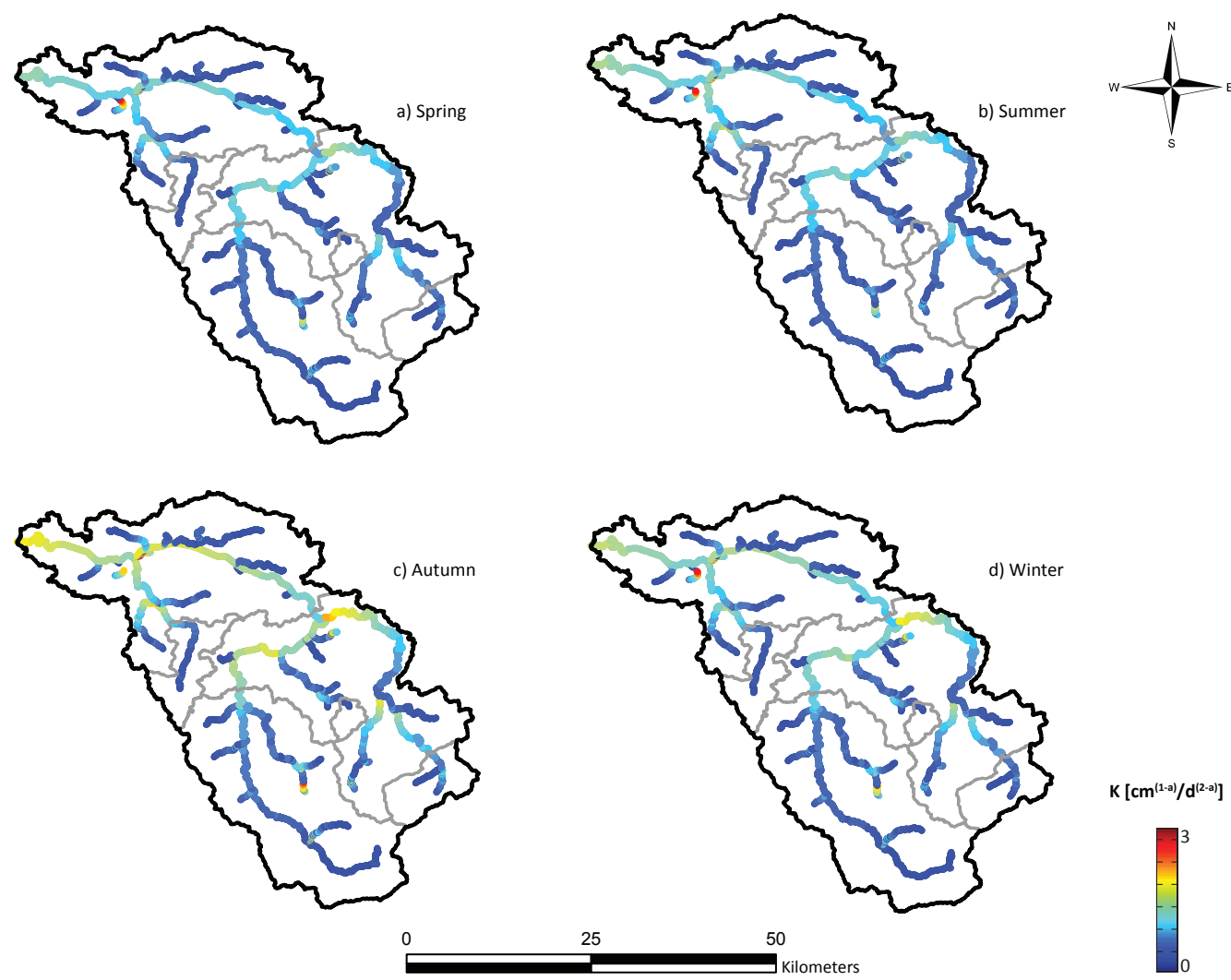

Figure 10: Spatial patterns of $K$ across the Thur basin, during all seasons, show an increasing trend towards the sub-catchment outlets. 

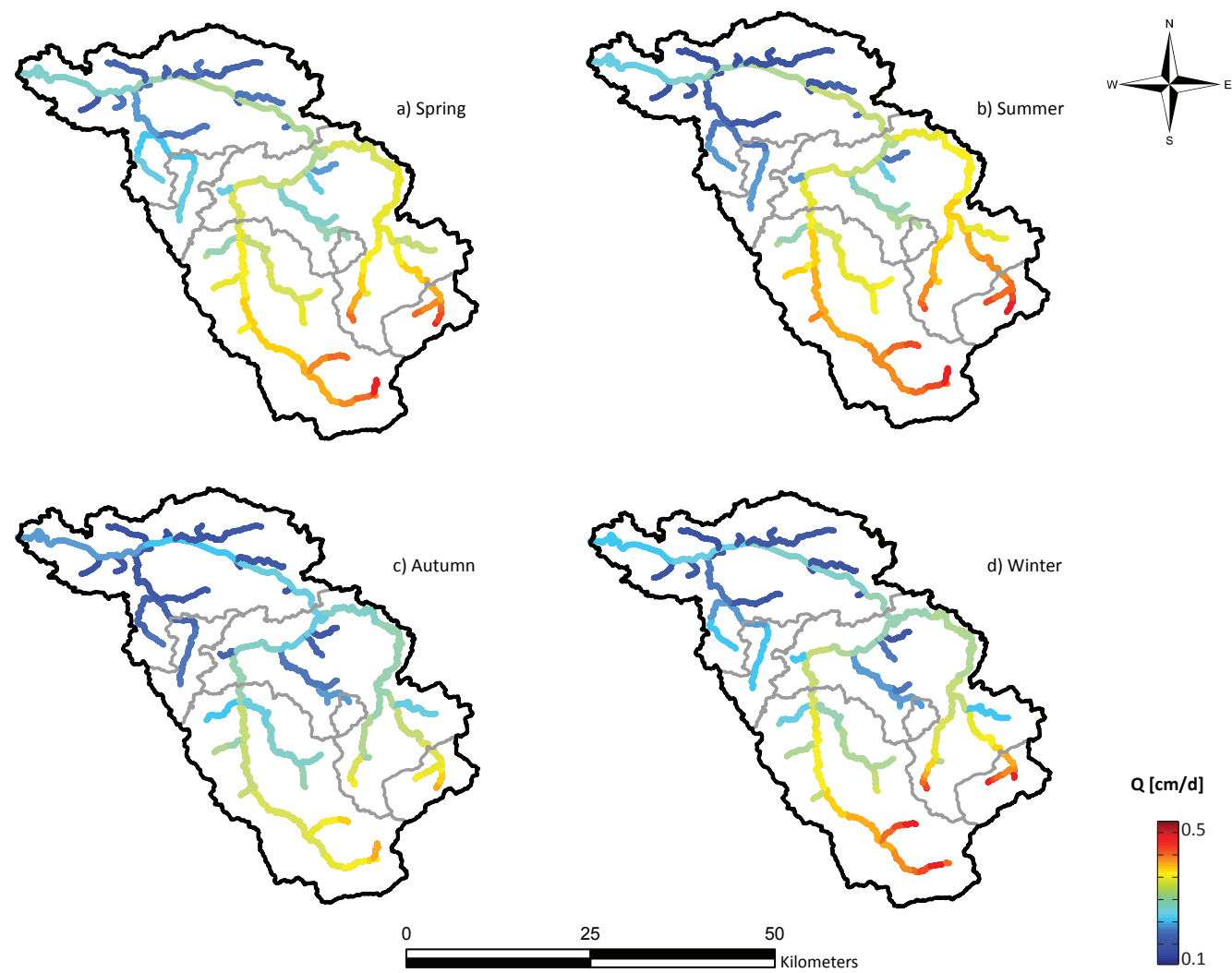

Figure 11: Spatial patterns of specific discharge $(\langle Q\rangle)$ across the Thur basin mirror the seasonality of the climate.

particularly in the main channel of the Thur river. The summer and autumn seasons display larger values of $C V_{Q}$ overall. These model outcomes point to larger variability of discharge in seasons with smaller frequency of events and larger rainfall intensity.

The pattern of streamflow regime along the river network is highlighted in Figure 13. 12 model estimated PDFs and CDFs of specific discharge for the autumn season along the main channel of the Thur river are depicted here. Congruous to previous results, the spatial patterns of the hydro-climatic drivers $(\alpha$ and $\lambda)$, lead to a decreasing trend of mean specific discharge and an increase of the PDF mode, from the headwaters towards the basin outlet. The joining of major tributaries along the channel can modulate the extent and the speed at which these changes occur. In agreement with observed data, a shift in the tail of the PDF from exponential (in the upstream location) to power-law 

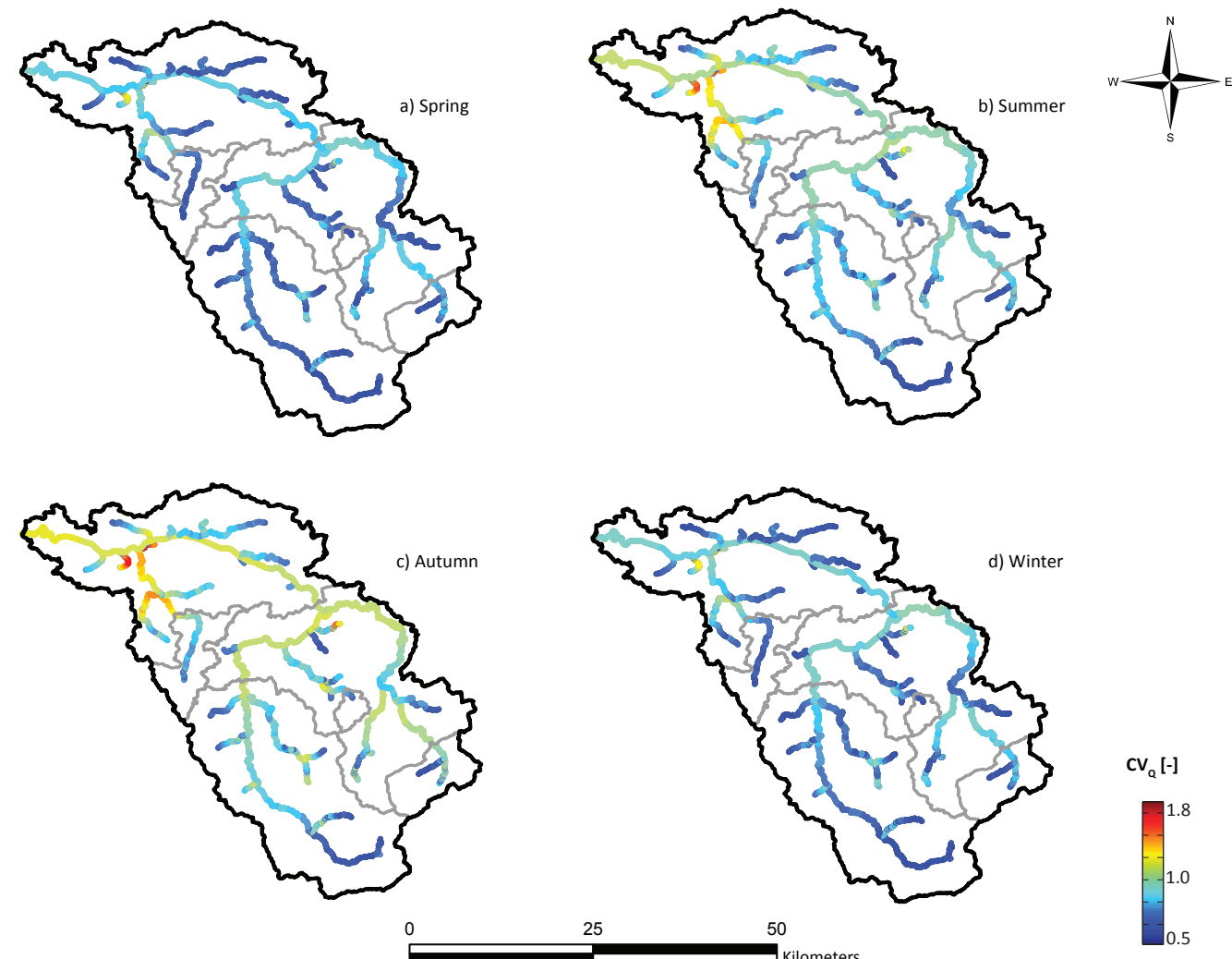

Figure 12: Map shows the distribution of $C V_{Q}$ throughout the Thur basin during all seasons. $C V_{Q}$ shows a complex pattern owing to the conflicting affects of the climatic and geomorphic drivers. 
(downstream) is noticeable in the CDF plot. This is in line with Basso et al. [2015], who have linked the emergence of heavy-tails to enhanced non-linearity of the catchment hydrologic response (regardless the underlying hydro-climatic regime), especially in cases where the recession exponent a is larger than 2. Hence, in this basin the range of variability of streamflow is not reduced with increasing contributing area, with implication to flooding potential in the lower regions of the Thur river.

The application discussed in this paper shows that the scaling of discharge variability with the catchment area, once the effect of catchment size is removed, may be far more complex than previously argued [Wolman and Miller, 1960; Molnar et al., 2006]. In fact, the flow regime is controlled by different intertwined factors, such as the frequency of events and recession properties, that in general exhibit contrasting patterns. Therefore, the scaling of discharge variability with catchment size may be strongly modulated by climatic gradients, in particular the spatial correlation of rainfall. This bears potential implications for the development of landscape evolution and sediment transport models, where a proper characterization of over-threshold events and discharge variability proves essential [Rossi et al., 2016; Basso et al., 2015; Lague et al., 2005].

\subsection{Scaling of recession parameters}

The results presented in the previous section show that the Thur catchment depicts pronounced inter-seasonal and spatial patterns in the climatic and recession drivers. While the climatic parameters show a strong seasonal pattern that seems to dominate the streamflow dynamics, the role of the recession parameters is more nuanced. This is particularly true in the cases where (as in this study) the catchment response shows pronounced non-linearity. The scaling of the recession parameters with respect to contributing area is an interesting question which would help the prediction of flow regimes through the extrapolation of discharge time series recorded in catchments featured by much smaller (or larger) contributing areas. While empirical power law relations have been proposed in the literature to link hydrograph's properties to catchment size, experimental data seems to show contradicting results. From this perspective, the available discharge data from the Thur basin and modeling exercise performed here offer a unique opportunity to investigate emerging scaling laws. 


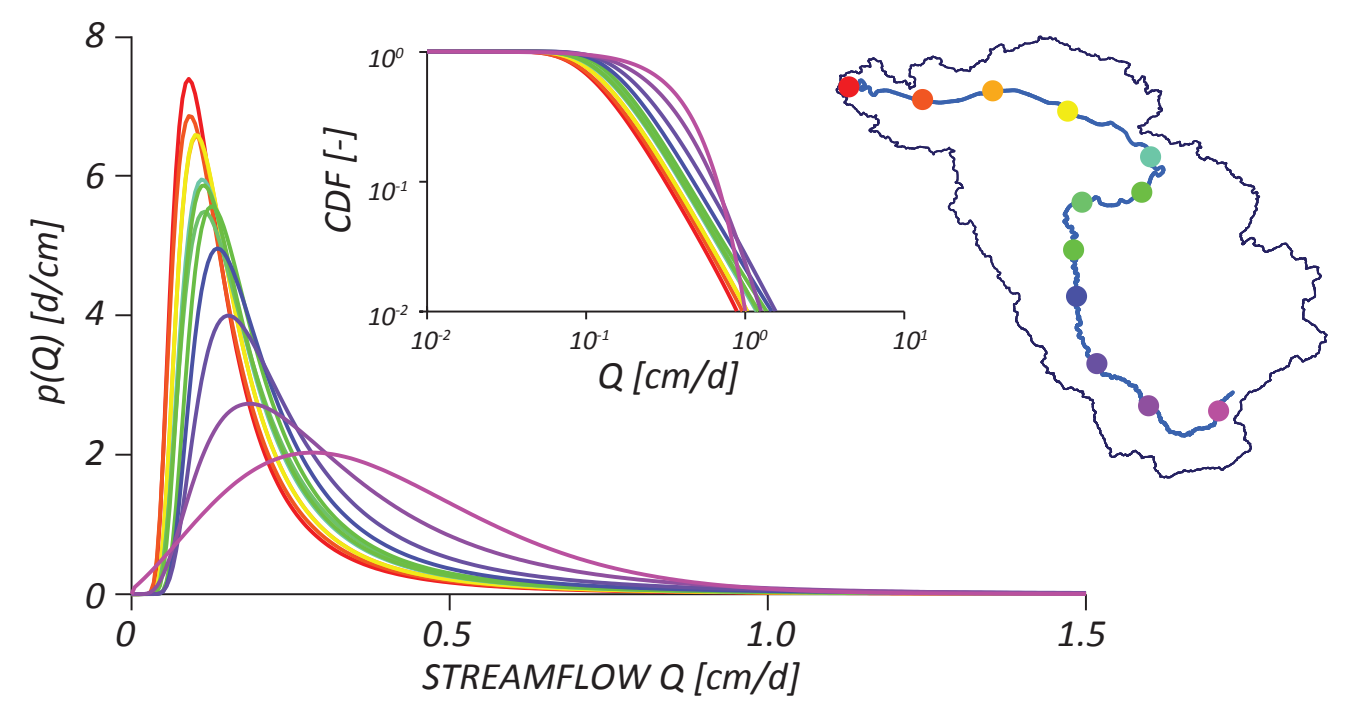

Figure 13: The pattern of flow regime along the main channel of the Thur river (from headwaters in Jonschwill to the catchment outlet in Andelfingen) depicted through the model estimated PDFs and CDFs of streamflows. The CDF plot is in a loglog scale. A decreasing trend $\langle Q\rangle$ and an increase of the PDF mode, from the headwaters towards the basin outlet, is noted.

Figure 14 presents the observed values of the recession exponent $a$ and coefficient $K$ versus the flow accumulation area for the set of nested sub-catchments: Jonschwil, Halden, and Andelfingen (see Figure 1b). These sub-catchments represent the contribution areas containing the main channel of the Thur river. Note that, the observed points have been derived from observed seasonal recessions and represent the average annual values for each sub-catchment. The results show an increasing pattern for both parameters, which highlights the observed increase in non-linearity in catchment response with increasing contribution area. This is in agreement with the findings of Harman et al. [2009], who related the increasing degree of non-linearity to heterogeneity of hydrologic response among different landscape units. This may also be the case for the Thur river, where strong climatic gradients possibly enhance the internal spatial heterogeneity of the hydrograph timescale.

The model estimated values of $a$ and $K$ for every point along the river network are plotted against flow accumulation area in Figure 15 and Figure 16, respectively. In order to better focus on the scaling patterns of recession parameters in the nested set 

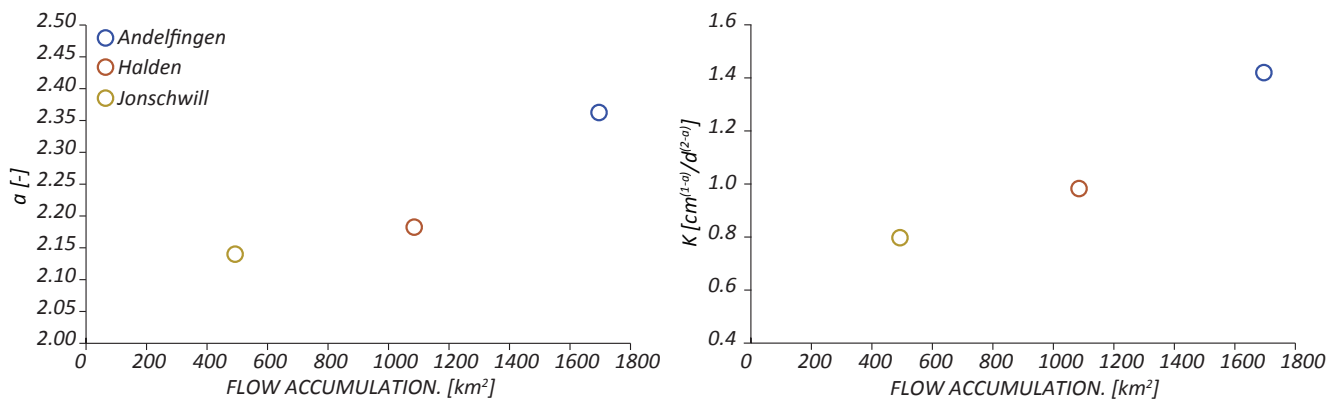

Figure 14: Observed values of the (a) recession exponent $a$ and (b) coefficient $K$ with respect to the contributing area for a set of nested sub-catchments in the Thur basin. Each point represents the averaged annual value for the sub-catchments.

of catchments considered, points corresponding to small contributing areas $\left(<50 \mathrm{~km}^{2}\right)$, which are present throughout the basin, have been omitted from the figures. The figures are organized with the largest sub-catchment on top to the smallest at the bottom.

In both cases, the large heterogeneity of data present in the smaller contributing areas is sharply reduced with increasing size. The discontinuities in the modeled points, and the corresponding "jumps" in model estimates of $a$ and $K$, occur where different tributaries merge and is consistent between the scaling patterns of both parameters. After each drop, the value increases again along single river reaches. This is because of the network becoming more elongated with increasing contributing area, which increases the nonlinearity in the relationship between $N$ and $G$. However, the slope of increase is reduced with increasing size. Overall, with increasing size there is a non-homogenous increasing pattern in the degree of non-linearity of the system, in agreement with observed data.

\section{Discussion}

The modeling approach presented here provide a novel method to estimate patterns of flow regimes and predict streamflow statistics at any arbitrary point along the river network using a parsimonious process bases formulation applicable to cases where long-term discharge time series are not available. This is a step forward particularly for studying ecohydrological processes that require a spatially explicit representation of streamflow properties. This is particularly true in cases where use of simple formulations is recom- 

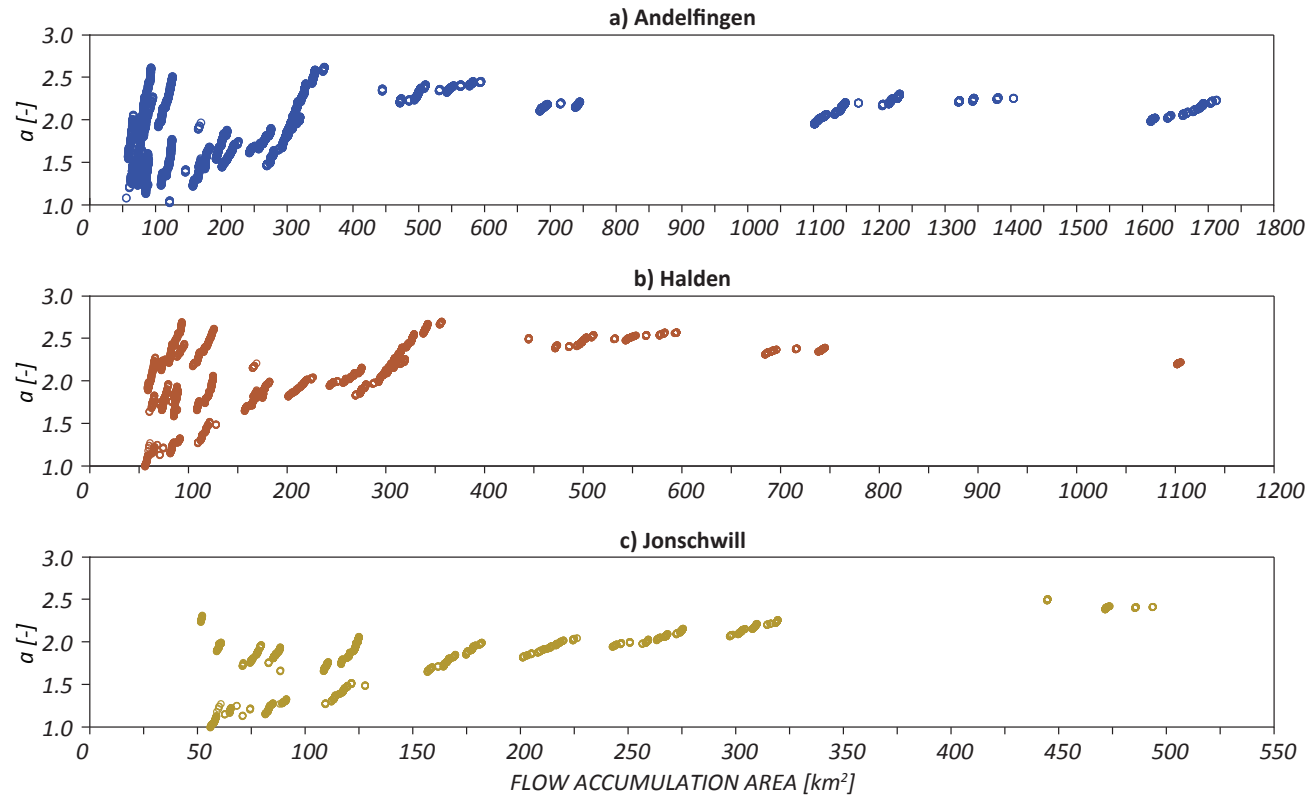

Figure 15: Model estimates of the recession exponent $a$ versus the contributing area for a set of nested sub-catchments (a) Andelfingen, (b) Halden, and (c) Jonschwil.
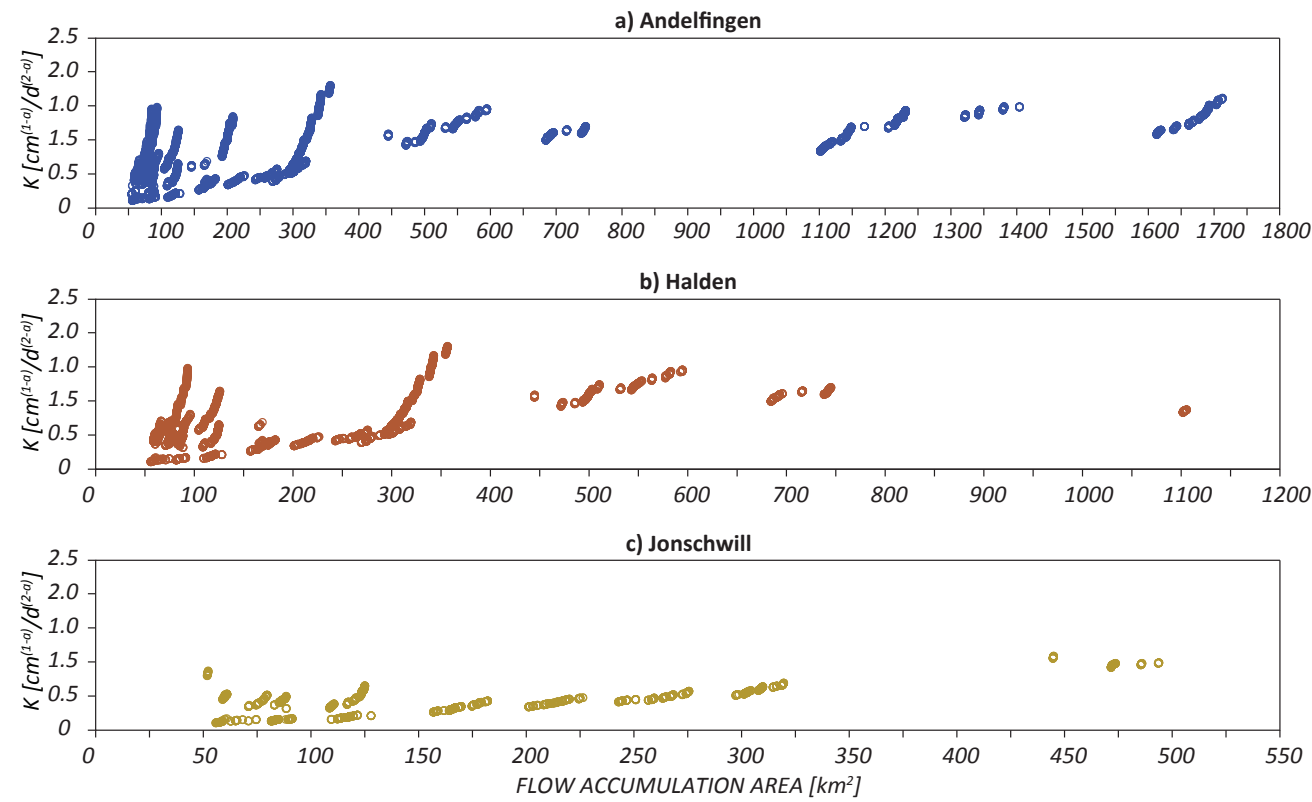

Figure 16: Average annual model estimates of the recession coefficient $K$ versus the contributing area for a set of nested sub-catchments (a) Andelfingen, (b) Halden, and (c) Jonschwil. 
mended, for example where the hydrologic output serves as the basis for ecological studies along river networks [Bertuzzo et al., 2009; 2011] or landscape evolution models, which are computationally intensive. Other approaches such as distributed models are able to predict specific events and can provide a more spatially detailed description of processes at multiple scales. However, application to data scarce settings may be challenging. The simplicity of statistical models makes them an attractive option, particularly for predicting specific metrics, if data requirements can be satisfied. The proposed framework is better suited for investigation of catchment scale patterns of streamflows and river management related issues, given the minimal calibration demand and limited data requirements.

The methods used for estimating each of the four parameters were selected among alternatives in the literature. The assumptions and limitations of each method have a large impact on the overall performance of the framework. The streamflow model assumes a Poisson distribution for the occurrence of rainfall events, with an exponential distribution of rainfall depths. The water balance model considers spatially averaged values of soil and vegetation parameters. The root depth parameter is also a representative value for the entire catchment that changes seasonally. Note that the streamflow model is weakly sensitive to root depth, and the robustness and performance of this approach has been extensively discussed in the literature [Botter et al., 2013 and references therein]. Rainfall fields were created through the IDW method, which provided the best mix of computational efficiency and accuracy in this case, though more sophisticated Kriging methods can be employed. The GRFM is based on the assumption that flow recession is driven by ADN dynamics, assumes the recession exponent to be constant through out the year, and estimates the recession coefficient through an empirical formula in relation to the mean discharge. These assumption have been previously highlighted in the method section and elaborated further in the references provided in Table 1. However, because the choice of method is independent of the overall set-up, it can be adjusted to the needs of each study, therefore, allowing the framework to be adaptable to different settings and data availability.

It is also noteworthy to mention that the Thur catchment and all the sub-catchments considered here are rain driven. This is true even in the winter season, but particularly in 
the melt season. Therefore, despite snow dynamics not being explicitly considered in the model formulation, seasonal variability is captured reasonably well. Alternative methods that explicitly account for snow dynamics, such as Schaefli et al,. 2013, require the introduction of additional calibrated parameters. Consideration of such methods would be appropriate in settings were snow accumulation and melting play a more prominent role in streamflow dynamics.

Lastly, the Thur basin, with a strongly persistent flow regime and non-linear hydrologic response, is well suited for the application of process based models such as the streamflow model considered here. While the overall framework is robust, statistical models may be more appropriate in regions with more heterogeneous recession behaviors across catchments [Müller and Thompson 2016].

\section{Conclusion}

In this study a modeling method for estimating flow duration curves, in the absence of calibration on discharge time series, was used to estimate streamflow distributions point-wise along the river network in the Thur basin, located in northeast Switzerland. The model proved capable of capturing, in a satisfactory manner, the seasonal dynamics of streamflows observed at six gauging stations after calibration of a single parameter pertaining to the water balance component of the model. The model was able to reproduce observed mean discharge $(\langle Q\rangle)$ rather well at these six stations, while the coefficient of discharge variability $C V_{Q}$ displayed more scattering. The strong seasonal patterns of the climatic parameters proved to be the dominant driver of streamflow dynamics. The spatial patterns of model parameters further highlighted the importance of the climatic drivers in determining the behavior of the flow regime along the river network. More frequent but much less intense events in the Swiss plateau lead to a decreasing trend of specific discharge with increasing contributing area. The seasonal variability of the streamflows showed a complex pattern which is influenced by climatic gradients and the increasing degree of non-linearity of the hydrologic response observed at larger spatial scales. The increasing non-linearity is possibly a by-product of the increasing heterogeneity of soil use and climate at larger scales, and leads to emergence of power law tails in the streamflow distribution of downstream sites. This study suggests that scaling 
laws for discharge variability and recession properties may be much more complex than previously suggested, as they exhibit strong climatic and geomorphic signatures.

This framework can be used for assessment of spatial variability of water resources within complex river systems and the evaluation of catchment-scale impact of river regulation. It represents the first step towards the development of a framework for comprehensibly describing catchment-scale ecohydrological processes using simple physically-based analytical models that do not require intensive calibration and computational burden. Other processes driven by streamflows (such as hydropower production, sediment transport, ecological dynamics, chemical fluxes, etc.) will be incorporated in future studies.

\section{Acknowledgments}

The research leading to these results was funded by the Swiss National Science Foundation (SNF, Projects No. 200021-149126). Additional support was provided by the Competence Center Environment and Sustainability (CCES) of the ETH domain in the framework of the RECORD and RECORD Catchment projects. Gianluca Botter acknowledges funding from project 60A09-4895/13 "Regimi idrologici e cambiamenti climatici". Special thanks to Stefano Basso for his indispensable support.

\section{References}

[1] Abbaspour, K. C., J. Yang, I. Maximov, R. Siber, K. Bogner, J. Mieleitner, J. Zobrist, R. Srinivasan (2007), Modelling hydrology and water quality in the pre-alpine/alpine Thur watershed using SWAT, J. Hydrol., 333, 413-430, doi:10.1016/j.jhydrol.2006.09.014.

[2] Basso, S., M. Schirmer, G. Botter (2015), On the emergence of heavy-tailed streamflow distributions, Adv. Water. Res., 82, doi:10.1016/j.advwatres.2015.04.013.

[3] Bertuzzo, E., R. Muneepeerakul, H. J. Lynch, W. F. Fagan, I. Rodriguez-Iturbe, A. Rinaldo (2009), On the geographic range of freshwater fish in river basins, Water Resour. Res., 45, W11420, doi:10.1029/2009WR007997.

[4] Bertuzzo, E., L. Mari, L. Righetto, M. Gatto, R. Casagrandi, M. Blokesch, I. Rodriguez-Iturbe, A. Rinaldo (2011), Prediction of the spatial evolution and effects of control measures for the unfolding Haiti cholera outbreak, Geophys. Res. Lett., 38, L06403, doi:10.1029/2011GL046823.

[5] Bertuzzo, E., L. Mari, L. Righetto, M. Gatto, R. Casagrandi, I. Rodriguez-Iturbe, A. Rinaldo (2012), Hydroclimatology of dual-peak annual cholera incidence: Insights from a spatially explicit model, Geophys. Res. Lett., 39, L05403, doi:10.1029/2011GL050723. 
[6] Biswal, B., and M. Marani (2010), Geomorphological origin of recession curves, Geophys. Res. Lett., 37, doi:10.1029/2010GL045415.

[7] Biswal, B., and M. Marani (2014), Universal recession curves and their geomorphological interpretation, Adv. Water. Res., doi:10.1016/j.advwatres.2014.01.004.

[8] Blöschl, G., M. Sivapalan, T. Wagener, A. Viglione, H. Savenije (Eds.), Runoff Prediction in Ungauged Basins, (2013), 1st ed, Cambridge University Press, doi:10.1017/CBO9781139235761.

[9] Botter, G., A. Porporato, I. Rodriguez-Iturbe, A. Rinaldo (2007), Basin-scale soil moisture dynamics and the probabilistic characterization of carrier hydrologic flows: Slow, leaching-prone components of the hydrologic response, Water. Resour. Res, 43, doi:10.1029/2006WR005043.

[10] Botter, G., A. Porporato, I. Rodriguez-Iturbe, A. Rinaldo (2009), Nonlinear storage-discharge relations and catchment streamflow regimes, Water. Resour. Res 45, doi:10.1029/2008WR007658.

[11] Botter, G., S. Basso, I. Rodriguez-Iturbe, A. Rinaldo (2013), Resilience of river flow regimes, Proc. Natl. Acad. Sci., doi:10.1073/pnas.1311920110.

[12] Brutsaert, W., and J. L. Nieber (1977), Regionalized drought flow hydrographs from a mature glaciated plateau, Water Resour. Res., 13, doi:10.1029/WR013i003p00637.

[13] Castellarin, A. (2014), Regional prediction of flow-duration curves using a three-dimensional kriging, J. of Hydrology, 513, 179-191, doi:10.1016/j.jhydrol.2014.03.050.

[14] Ceola, S., E. Bertuzzo, G. Singer, T. J. Battin, A. Montanari, A. Rinaldo (2014), Hydrologic controls on basinscale distribution of benthic invertebrates, Water Resour. Res., 50, 29032920, doi:10.1002/2013WR01511.

[15] Cirpka, O. A., M. N. Fienen, M. Hofer, E. Hoehn, A. Tessarini, R. Kipfer, P. K. Kitanidis (2007), Analyzing bank filtration by deconvoluting time series of electric conductivity, Ground Water, 45, 318-328, doi:10.1111/j.1745-6584.2006.00293.x.

[16] Doulatyari, B., A. Betterle, S. Basso, B. Biswal, M. Schirmer, G. Botter (2015), Predicting streamflow distributions and flow duration curves from landscape and climate, Adv. Water. Res., doi:10.1016/j.advwatres.2015.06.013.

[17] Flügel, W. A. (1995), Delineating hydrological response units by geographical information system analyses for regional hydrological modelling using PRMS/MMS in the drainage basin of the river Bröl Germany, Hydro. Processes, 9, 423436, doi:10.1002/hyp.3360090313.

[18] Formetta G., A. Antonello, S. Franceschi, O. David, R. Rigon (2014), Hydrological modelling with components: A GIS-based open-source framework, Environ. Model. Softw., 55, 190-200, 1364-8152, doi:10.1016/j.envsoft.2014.01.019.

[19] Götzinger, J., A. Bárdossy (2006), Comparison of four regionalisation methods for a distributed hydrological model, J. of Hydrology, 333, 374-384, doi:10.1016/j.jhydrol.2006.09.008.

[20] Gurtz, J., H. Lang, M. Verbunt, M. Zappa (2005), The use of hydrological models for the simulation of climate change impacts on mountain hydrology. In: Huber, U.M., Bugmann, H.K.M., Reasoner, M.A. (Eds.), Global Change and Mountain Regions - An Overview of Current Knowledge, Springer, Dordrecht, NL, pp. 343354.

[21] Harman, C. J., M. Sivapalan, P. Kumar (2009), Power law catchment-scale recessions 
arising from heterogeneous linear small-scale dynamics, Water Resour. Res., 45, W09404, doi:10.1029/2008WR007392

[22] Hayashi, M., T. Vogt, L. M“chler, M. Schirmer (2012), Diurnal fluctuations of electrical conductivity in a pre-alpine river: Effects of photosynthesis and groundwater exchange, J. Hydrol., 450451, 93104, doi:10.1016/j.jhydrol.2012.05.020.

[23] Jaeger, K. L., J. D. Oldenb, N. A. Pellandc (2014), Climate change poised to threaten hydrologic connectivity and endemic fishes in dryland streams, Proc. Natl. Acad. Sci., doi/10.1073/pnas.1320890111.

[24] Kirchner, J. W. (2009), Catchments as simple dynamical systems: catchment characterization, rainfall-runoff modeling, and doing hydrology backward, Water Resour. Res., 45, doi:10.1029/2008WR006912.

[25] Kling, H., and H. Gupta (2009), On the development of regionalization relationships for lumped watershed models: The impact of ignoring sub-basin scale variability, J. of Hydrology, 373, 337-351, doi:10.1016/j.jhydrol.2009.04.031.

[26] Kumar, R., L. Samaniego, S. Attinger (2013), Implications of distributed hydrologic model parameterization on water fluxes at multiple scales and locations, Water Resour. Res., 49, doi:10.1029/2012WR012195.

[27] Lague, D., N. Hovius, P. Davy (2005), Discharge, discharge variability, and the bedrock channel profile, J. Geophys. Res., 110, doi:F04006, doi:10.1029/2004JF000259.

[28] Laaha, G., J. O. Skoien, G. Blöschl (2014), Spatial prediction on river networks: comparison of top-kriging with regional regression, Hydrol. Process., 28, 315324, doi:10.1002/hyp.9578.

[29] McCluney, K. E., N. L. Poff, M. A. Palmer, J. H. Thorp, G. C. Poole, B. S. Williams, M. R. Williams, J. S. Baron (2014), Riverine macrosystems ecology: sensitivity, resistance, and resilience of whole river basins with human alterations, Front. Ecol. Environ., 12, 4858, doi:10.1890/120367.

[30] Molnar, P., R. S. Anderson, G. Kier, J. Rose (2006), Relationships among probability distributions of stream discharges in floods, climate, bed load transport, and river incision, J. Geophys. Res., 111, F02001, doi:10.1029/2005JF000310.

[31] Müller, M. F., D. N. Dralle, S. E. Thompson (2014), Analytical model for flow duration curves in seasonally dry climates, Water Resour. Res., 50, 55105531, doi:10.1002/2014WR015301, 2014.

[32] Müller, M. F., and S. E. Thompson (2015), TopREML: a topological restricted maximum likelihood approach to regionalize trended runoff signatures in stream networks, Hydrol. Earth Syst. Sci., 19, 2925-2942, doi:10.5194/hess-19-2925-2015.

[33] Müller, M. F. and S. E. Thompson (2016), Comparing statistical and process-based flow duration curve models in ungauged basins and changing rain regimes, Hydrol. Earth Syst. Sci., 20, 669-683, doi:10.5194/hess-20-669-2016.

[34] Müller, M. F., S. E. Thompson, M. N. Kelly (2016), Bridging the information gap: A webGIS tool for rural electrification in data-scarce regions, Appl. Energy, 171, 277-286, doi:10.1016/j.apenergy.2016.03.052.

[35] Muneepeerakul, R., J. S. Weitz, S. A. Levin, A. Rinaldo, I. Rodriguez-Iturbe (2007), A neu- 
tral metapopulation model of biodiversity in river networks, J. Theor. Biol., 245, 351363 , doi:10.1016/j.jtbi.2006.10.005.

[36] Murphy, J. C., R. R. Knight, W. J. Wolfe, W. S. Gain (2013), Predicting Ecological Flow Regime at Ungaged Sites: A Comparison of Methods, River Res. Applic., 29, 660669, doi:10.1002/rra.2570.

[37] Porporato, A. , and L. Ridolfi (2003), Detecting determinism and non linearity in river flow time series, Hydrol. Sci. J., 48, 76380, doi:10.1623/hysj.48.5.763.51457.

[38] Porporato, A., E. Daly, I. Rodriguez-Iturbe (2004), Soil water balance and ecosystem response to climate change. Am. Nat., 164, doi:org/10.1086/424970.

[39] Pugliese, A., A. Castellarin, A. Brath (2014), Geostatistical prediction of flowduration curves in an index-flow framework, Hydrol. Earth Syst. Sci., 18, 3801-3816, doi:10.5194/hess-18-3801-2014.

[40] Pumo, D., L. Noto, F. Viola (2013), Ecohydrological modelling of flow duration curve in Mediterranean river basins, Adv. Water Resour., 52, 314327, doi:10.1016/j.advwatres.2012.05.010.

[41] Rodriguez-Iturbe, I. (2000), Ecohydrology: A hydrologic perspective of climate-soil-vegetation dynamies, Water Resour. Res., 36(1), 39, doi:10.1029/1999WR900210.

[42] Rossi, M. W., K. X. Whipple, E. R. Vivoni (2016), Precipitation and evapotranspiration controls on daily runoff variability in the contiguous United States and Puerto Rico, J. Geophys. Res. Earth Surf., 121, 128145, doi:10.1002/2015JF003446.

[43] Ryo, M., Y. Iwasaki, C. Yoshimura, V. O. C. Saavedra (2015), Evaluation of spatial pattern of altered flow regimes on a river network using a distributed hydrological model, PLoS ONE, doi:10.1371/journal.pone.0133833.

[44] Samaniego, L., R. Kumar, S. Attinger (2010), Multiscale parameter regionalization of a grid-based hydrologic model at the mesoscale, Water Resour. Res., 46, W05523, doi:10.1029/2008WR007327.

[45] Seneviratne, S. I., I. Lehner, J. Gurtz, A. J. Teuling, H. Lang, U. Moser, D. Grebner, L. Menzel, K. Schroff, T. Vitvar, M. Zappa (2012), Swiss prealpine Rietholzbach research catchment and lysimeter: 32 year time series and 2003 drought event, Water Resour. Res., 48, W06526, doi:10.1029/2011WR011749.

[46] Schaefli, B., L. Nicótina, C. Imfeld, P. Da Ronco, E. Bertuzzo, A. Rinaldo (2014) a Spatially Explicit Hydrologic Response model for ecohydrologic applications, Geosci. Model Dev., 7, 2733-2746, doi:10.5194/gmd-7-2733-2014.

[47] Schaefli, B., A. Rinaldo, G. Botter (2013), Analytic probability distributions for snow-dominated streamflow, Water Resour. Res., 49, 27012713, doi:10.1002/wrcr.20234.

[48] Schneider, P., T. Vogt, M. Schirmer, J. Doetsch, N. Linde, N. Pasquale, P. Perona, O. A. Cirpka (2011), Towards improved instrumentation for assessing river-groundwater interactions in a restored river corridor, Hydrol. Earth Syst. Sci., 15, 2531-2549, doi:10.5194/hess-15-2531-2011.

[49] Seiz, G., N. Foppa (2007), National Climate Observing System (GCOS Switzerland), Publication of MeteoSwiss and ProClim, p.92, available online:http://www.gcos.ch.

[50] Shaw, S. B., T. M. McHardy, S. J. Riha (2013), Evaluating the influence of watershed moisture storage on variations in base flow recession rates during prolonged rain-free periods in medium-sized catchments in New York and Illinois, USA, Water Resour. Res., 49, 60228 doi:10.1002/wrcr.20507. 


\section{Appendix A. Hydrodynamic Stations}

Table A.1: List of all sub-catchments in the Thur basin. Station Andelfingen represents the outlet for the entire basin. The discharge station location is mentioned in the CH1903 (LV03) coordinate system.

\begin{tabular}{cccccc}
\hline $\begin{array}{c}\text { Catchment and } \\
\text { Discharge Station ID }\end{array}$ & Tributary ID & Area $\left[\mathrm{km}^{2}\right]$ & $\mathbf{X}$ & $\mathbf{Y}$ & $\langle Q\rangle$ \\
\hline Andelfingen & Thur & 1700 & 693510 & 272500 & 0.24 \\
Appenzell & Sitter & 74 & 749040 & 244220 & 0.34 \\
Halden & Thur & 1085 & 733560 & 263180 & 0.30 \\
Herisau & Glat & 17 & 737270 & 251290 & 0.30 \\
Jonschwil & Thur & 493 & 723675 & 252720 & 0.36 \\
Wängi & Murg & 80 & 714105 & 261720 & 0.20 \\
\hline
\end{tabular}


Table A.2: List of all rainfall gauging stations and their location in the CH1903 (LV03) coordinate system.

\begin{tabular}{|c|c|c|c|c|c|c|}
\hline Name & $\mathbf{X}$ & $\mathbf{Y}$ & $\begin{array}{l}\text { Min annual } \\
\text { value }[\mathbf{c m}]\end{array}$ & $\begin{array}{c}\text { Max annual } \\
\text { value }[\mathrm{cm}]\end{array}$ & $\begin{array}{c}\text { Mean annual } \\
\text { average }\end{array}$ & $\begin{array}{c}\text { Mean annual } \\
\text { cumulative sum }\end{array}$ \\
\hline Affeltrangen & 719069 & 265660 & 0 & 9.37 & 0.27 & 99.02 \\
\hline Andelfingen & 693809 & 273070 & 0 & 12.15 & 0.24 & 87.93 \\
\hline Appenzell & 747734 & 244475 & 0 & 13.40 & 0.45 & 163.04 \\
\hline Bischofszell & 735324 & 262285 & 0 & 10.91 & 0.28 & 102.42 \\
\hline Eeschlikon & 715694 & 256830 & 0 & 10.27 & 0.34 & 125.00 \\
\hline Flawil & 733139 & 252930 & 0 & 14.30 & 0.34 & 124.71 \\
\hline Frauenfeld & 709479 & 270170 & 0 & 12.86 & 0.29 & 104.15 \\
\hline Herisau & 737729 & 250830 & 0 & 11.75 & 0.38 & 138.97 \\
\hline Illhart & 720328 & 275760 & 0 & 12.26 & 0.27 & 99.11 \\
\hline Kalchrain & 709058 & 274350 & 0 & 14.32 & 0.27 & 97.35 \\
\hline Niederneunforn & 700859 & 272510 & 0 & 11.26 & 0.24 & 87.42 \\
\hline Ricken & 721599 & 236075 & 0 & 15.21 & 0.50 & 181.81 \\
\hline Säntis & 744100 & 234900 & 0 & 18.67 & 0.70 & 245.01 \\
\hline Starkenbach & 737699 & 227600 & 0 & 15.40 & 0.52 & 188.34 \\
\hline Stpeterzell & 731249 & 242140 & 0 & 13.68 & 0.44 & 160.91 \\
\hline Sulgen & 731024 & 267175 & 0 & 9.60 & 0.28 & 101.99 \\
\hline Teufen & 747809 & 250410 & 0 & 13.45 & 0.42 & 151.88 \\
\hline Urnäsch & 738679 & 241230 & 0 & 12.00 & 0.48 & 175.49 \\
\hline Weinfelden & 725424 & 268935 & 0 & 11.74 & 0.26 & 96.44 \\
\hline
\end{tabular}

\section{Appendix B. Database Architecture}

Figure B.1 presents the overall structure of the database and Web-GIS platform (see Table B.1 for more details). The database utilizes PostgreSQL for storing and retrieving data, and PostGIS for interactions with geospatial data. All data was gathered and then standardized for format and units. Particular attention was required for identification and uniform treatment of datasets where no data was available in the time series in order to prevent inconsistencies. The application server is charged with data management and analysis. GeoServer acts as a middle layer between the database and the GUI. It also allows for central management and publishing of all data in different standard formats defined by Open Geospatial Consortium. The type of data (input or output) displayed in the GUI, coordinate reference system definition and re-projection, styling and labeling, and basic metadata information are also managed here. GeoWebCache is used to cache maps, from all publicly available data sources incorporated here, in 
order to accelerate and optimize map image delivery. Grass-GIS is used as a back-end web processing service to create functions for the various parameterization methods and integrate them in the overall framework. Since the Thur basin spans approximately 9 million pixels, functions were coded in a parallelized method to exploit multi-core CPU capabilities and to permit background execution. A PHP (scripting language) rapid application development framework and GeoEXT were utilized in the implementation of Web-GIS platforms. All online published graphs were created on the fly through Dygraphs JavaScript charting library. See Table B.1 for more details.

Development of GIS based tools for predicting of hydrological properties at the basin scale significantly increases the reach of this research for practitioners [e.g. Formetta et al., 2014; Müller and Thompson 2015; Müller et al., 2016]. Likewise, the geo-database and Web GIS platform developed here, can be applied as a complete package to different catchments provided that the minimal data requirements are satisfied. The modular design employed in this platform allows for versatility in the type and number of methods used for estimating model parameters. It also provides the ability to consider multiple scenarios using different sets of data. The output of the model can be easily extracted and manipulated to serve other types of GIS-based models. We believe this approach can serve water managers and public administrations for developing catchment-scale management strategies and optimizing allocation of water resources. 


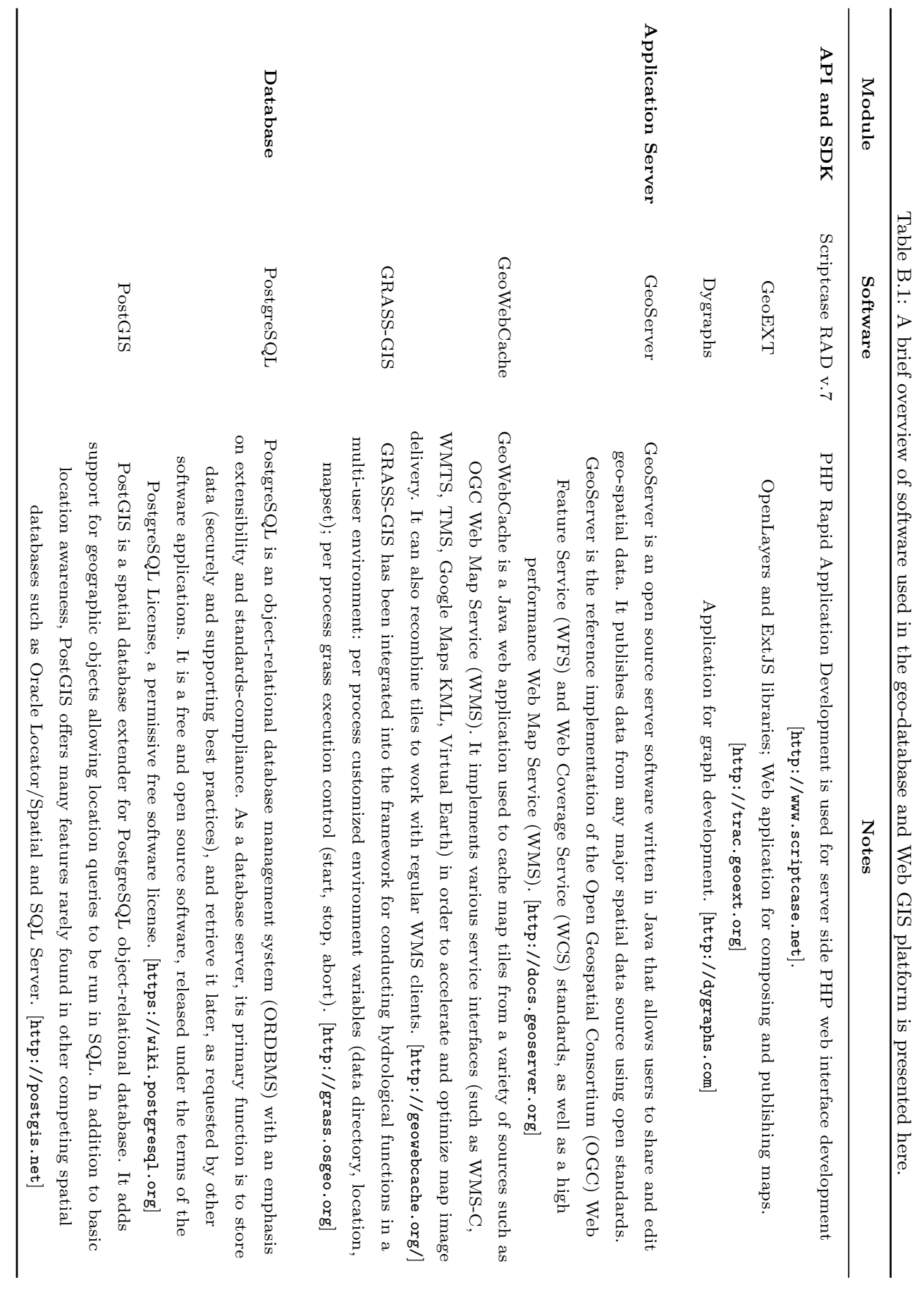




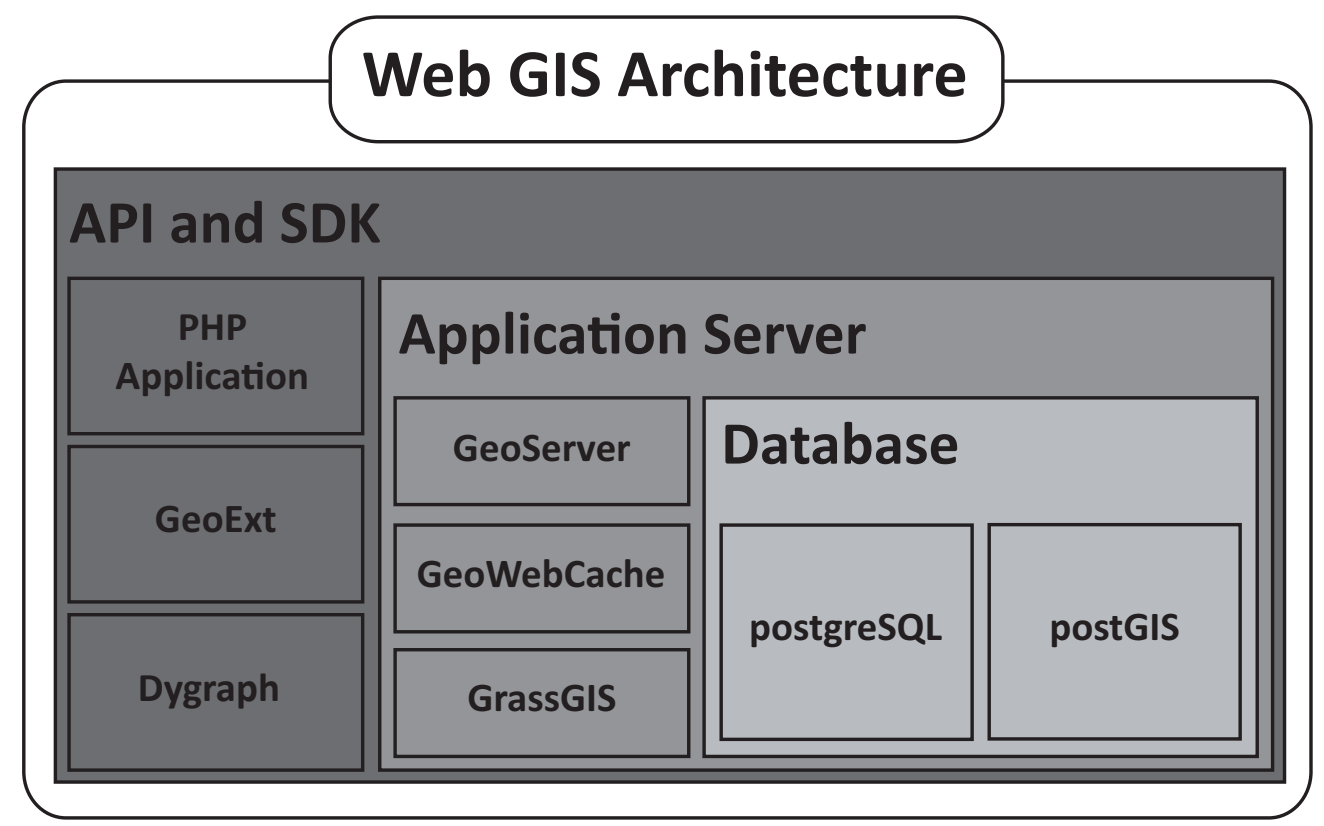

Figure B.1: Structure of the geo-database and Web GIS platform.

\section{Appendix C. Variability of sample $C V_{Q}$ for distributions with infinite vari-} ance

In Section 5 we discussed the divergence of the analytical formulation of variance based on the quation for $p(Q)$ The coefficient of variation of daily streamflows $C V_{Q}$ is an important indicator for the behavior of the flow regimes. Hence, the impact of this divergence on variability of sample $C V_{Q}$ was further explored through a Monte Carlo method. For each season at each of the six sub-catchment outlets, a 40 year randomized synthetic time series of discharge was created based on observed values of the four main model parameters $(\lambda, \alpha, a, K)$. This was repeated 100 times and streamflow statistics were then calculated at each outlet. The moments of the analytical PDF were calculated through numerical integration and results were averaged. Figure C.1 depicts the variability of estimated seasonal $C V_{Q}$ at each outlet by means of box-plots . The observed value of $C V_{Q}$ (blue line) is also shown. In most cases, the observed value of $C V_{Q}$ falls within the predicted range of variability produced by the model. The poor performance of Herisau, while noticeable, is expected. The analytical formulation of variance in this 


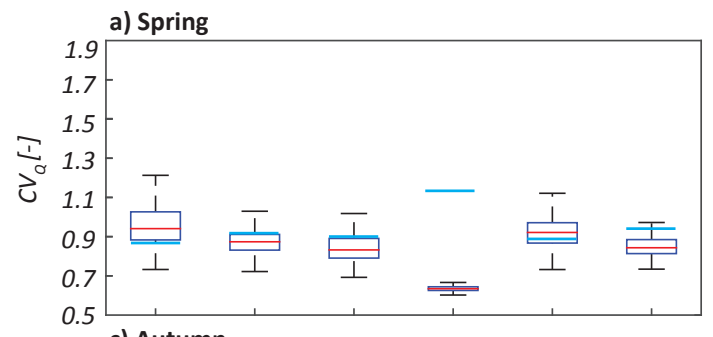

b) Summer
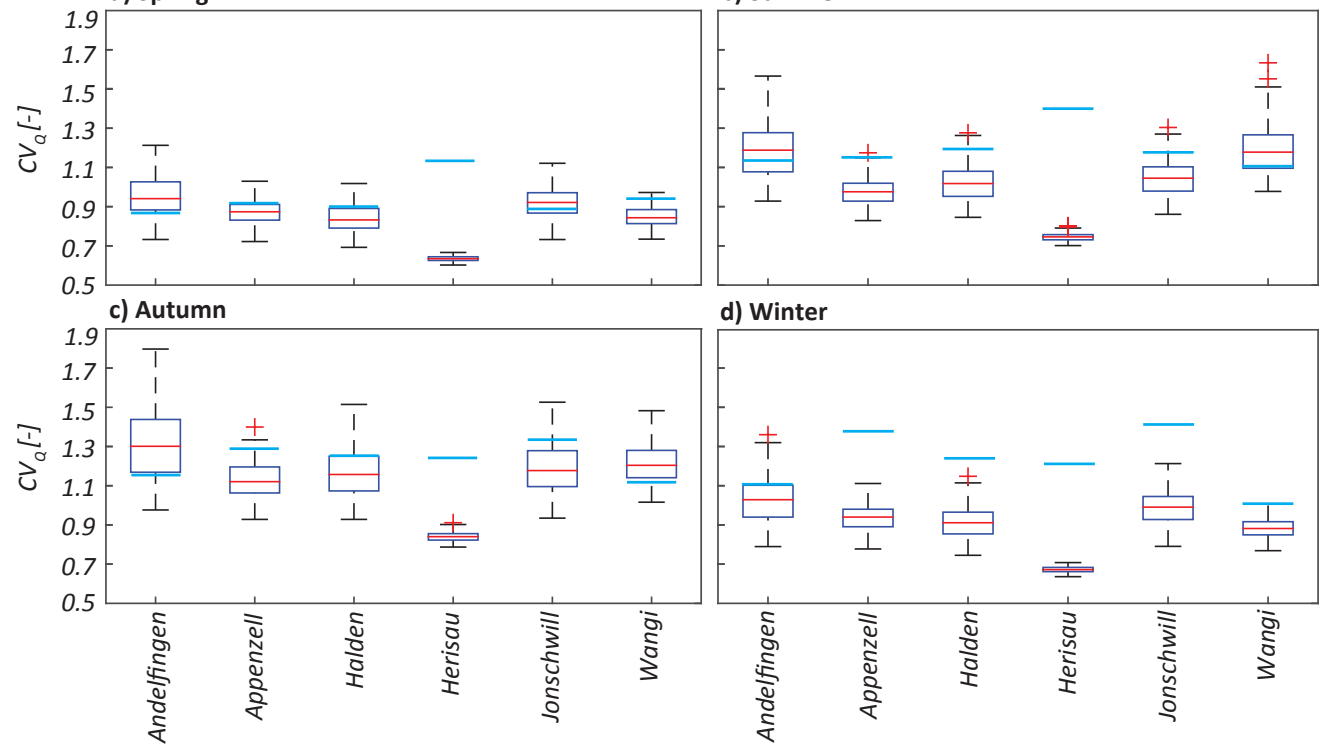

d) Winter

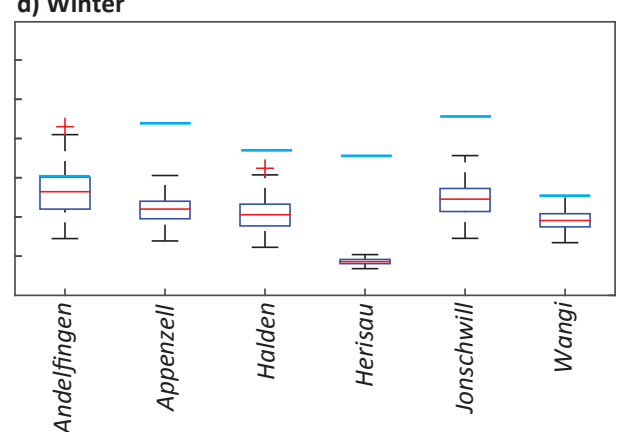

Figure C.1: The box plots show the 25\%, 50\% and 75\% quartiles as well as the entire range of observed values across the seasons for all six sub-catchments. The blue lines represent the value of $C V_{Q}$ calculated based on the observed discharge time series.

case is in fact convergent, since the value of the recession coefficient $a$ is less than 2 . This can instead be attributed to a poor representation of the recession dynamics at low flow conditions and very high flows for this sub-catchment. Furthermore, the results in the winter are generally less robust than the other seasons which is associated with the lower performance of the water balance model in this season. 